Article

\title{
New Interface for Assessing Wellbore Stability at Critical Mud Pressures and Various Failure Criteria: Including Stress Trajectories and Deviatoric Stress Distributions
}

\author{
Jihoon Wang ${ }^{1,2, *}$ and Ruud Weijermars ${ }^{3}$ \\ 1 Department of Petroleum and Natural Gas Engineering, New Mexico Institute of Mining and Technology, \\ 801 Leroy Place, Socorro, NM 87801, USA \\ 2 Department of Earth Resources and Environmental Engineering, Hanyang University, 222, Wangsimni-ro, \\ Seongdong-gu, Seoul 04763, Korea \\ 3 Harold Vance Department of Petroleum Engineering, Texas A\&M University, 3116 TAMU, College Station, \\ TX 77843-3116, USA; r.weijermars@tamu.edu \\ * Correspondence: jihoon.wang@nmt.edu; Tel.: +1-575-835-5289
}

Received: 18 September 2019; Accepted: 16 October 2019; Published: 22 October 2019

check for updates

\begin{abstract}
This study presents a new interface for wellbore stability analysis, which visualizes and quantifies the stress condition around a wellbore at shear and tensile failure. In the first part of this study, the Mohr-Coulomb, Mogi-Coulomb, modified Lade and Drucker-Prager shear failure criteria, and a tensile failure criterion, are applied to compare the differences in the critical wellbore pressure for three basin types with Andersonian stress states. Using traditional wellbore stability window plots, the Mohr-Coulomb criterion consistently gives the narrowest safe mud weight window, while the Drucker-Prager criterion yields the widest window. In the second part of this study, a new type of plot is introduced where the safe drilling window specifies the local magnitude and trajectories of the principal deviatoric stresses for the shear and tensile wellbore failure bounds, as determined by dimensionless variables, the Frac number $(F)$ and the Bi-axial Stress scalar $(\chi)$, in combination with failure criteria. The influence of both stress and fracture cages increases with the magnitude of the $F$ values, but reduces with depth. The extensional basin case is more prone to potential wellbore instability induced by circumferential fracture propagation, because fracture cages persists at greater depths than for the compressional and strike-slip basin cases.
\end{abstract}

Keywords: wellbore stability; failure criteria; stress trajectories; safe drilling window; Frac number; Biaxial-Stress scalar

\section{Introduction}

Reliable analysis of wellbore stability is one of the keys for a successful and safe drilling process, because if instability occurs it may result in pipe stuck by wellbore collapse or drilling fluid loss through induced tensile fractures, which require considerable time and effort to be solved. When a well is drilled in an elastic rock formation, the stresses around the wellbore are redistributed by replacement of rock with drilling fluid and its condition is altered from the intrinsic state. The redistributed stress magnitudes are generally calculated by the classical Kirsch equations, accounting for the in-situ stresses and wellbore pressure induced by drilling fluid weight. The stresses and the wellbore pressures are next integrated with rock failure criteria to compute the safe mud weight window. Outside the safe mud weight window, the stresses on the wellbore induce failure and wellbore stability becomes compromised. 
Although commercial packages for wellbore stability (WBS) analysis adequately follow the above procedure, we argue that there is still room for improvement in the information flow assessed for making WBS control decisions. This study advocates an approach where one carefully examines the stress trajectories when failure occurs at the upper and lower bounds of the safe drilling window. Knowing the stress trajectory pattern at the moment of failure is extremely useful as it provides additional conceptual insight and quantitative information relevant for real-time stability analysis during drilling and completion processes. The new WBS interface and examples presented in our study led to several new practical insights, which are systematically discussed based on our in-depth analysis.

The first part of our study compares the variations in the safe drilling envelope, using traditional WBS plots, for the four commonly used shear failure criteria augmented with a fifth, tensile failure criterion, under various basin stress states, first recognized by Anderson (see references in Thomas and Weijermars [1]). Andersonian stress states typical for each type of basin are generated on the basis of published field data for such basins. Next, the safe drilling window and the critical wellbore pressures at lower-bound and upper-bound shear failure are calculated for each Andersonian case using four different shear failure criteria: The Mohr-Coulomb, Mogi-Coulomb, modified Lade, and Drucker-Prager criterion. In addition, the wellbore pressure at tensile failure is calculated. According to our knowledge such a systematic comparative study of shear and tensile failure criteria and the resulting critical wellbore pressures, with an analysis of the shifts in the safe drilling window under the three principal Andersonian stress regimes, has not been done before.

The second part of the paper analyzes the detailed principal stress trajectory patterns and magnitudes at failure for various depths in the wellbore (up to $3048 \mathrm{~m}$ depth), and introduces the new WBS interface (advocated here for the first time). In traditional wellbore stability analysis, the only parameters of focus are the principal total stress concentrations at the wellbore proper, which are used to determine whether the wellbore pressure would induce a failure under a given circumstance of the in-situ stresses. The principal stress trajectories are commonly neglected but harness valuable information such as the expected location of failure and likely fracture propagation direction [2]. Previous research [1] dealing with the deviatoric stress trajectories patterns was limited to an evaluation of the possible range of outcomes in a sensitivity analysis using arbitrary input values ( $\chi$ and $F$, see Section 4), but did not show how these parameters may vary in a practical wellbore stability analysis. The present study visualizes the principal deviatoric stress magnitudes and trajectories at the margins of the safe drilling envelope for a vertical wellbore under three different Andersonian tectonic stress regimes.

\section{Preparation of Wellbore Stability Model}

Essential blocks for our proposed expansion of the classical wellbore stability model are discussed in the sections below. Prior to the stress distribution analysis around the wellbore, data from field cases in literature were gathered to select reasonable ranges of the in-situ stresses and rock failure properties. The selected field studies were used as a basis for constructing three synthetic Andersonian stress states (Section 2.1). The four failure criteria used in our wellbore stability analysis are briefly reviewed (Section 2.2). All pertinent equations used in the wellbore stability model are summarized in concise Appendices A-C, and a supplementary online file for quick referral, and to maintain the brevity of the main text.

\subsection{Construction of Three Synthetic Andersonian Cases}

In order to determine the reasonable in-situ stress conditions with rock mechanical properties, field scale measurements available in literature have been reviewed (described in detail in Appendix A). The in-situ vertical, maximum, and minimum stress gradients collected from field data have ranges of 22.6-25.6, 17.0-34.4, and 14.3-24.4 kPa/m, respectively (Table 1). In addition, the pore pressure gradients, cohesion, internal friction angle, and Poisson's ratio are in the ranges of $9.3-10.4 \mathrm{kPa} / \mathrm{m}$, 5.4-12.4 MPa, $31.0-50.2^{\circ}$, and $0.18-0.30$, respectively (Table 1 ). Assuming that the in-situ stress gradients 
are consistent from the surface to $3048 \mathrm{~m}(10,000 \mathrm{ft})$ depth, synthetic 1D models for the three synthetic Andersonian cases were constructed based on the collected field data (Table 2).

The vertical stress and pore pressure gradients range between 22.6 and $10.2 \mathrm{kPa} / \mathrm{m}$ along the wellbore trajectory. Since this study focuses on vertical wellbores, the difference between the principal stresses normal to the wellbore, i.e., $\sigma_{H}-\sigma_{h}$, is consistently set as $4.5 \mathrm{kPa} / \mathrm{m}$ for all the cases. For the reverse faulting regime, the maximum and the minimum horizontal stresses are 29.4 and $24.9 \mathrm{kPa} / \mathrm{m}$, respectively. The maximum and minimum horizontal stress gradients are 24.9 and $20.4 \mathrm{kPa} / \mathrm{m}$ for the strike-slip regime, and 20.4 and $15.8 \mathrm{kPa} / \mathrm{m}$ for the normal faulting regime. The cohesion is assumed to be $6.9 \mathrm{MPa}$, with an internal friction angle of $40^{\circ}$, and a Poisson's ratio of 0.25 . For the tensile failure computations, we assume that the tensile strength is zero as a general approximation [3].

Table 1. In-situ stresses and rock mechanical properties from available literature. Assumed values are underlined.

\begin{tabular}{|c|c|c|c|c|c|c|c|c|}
\hline Location & $\begin{array}{l}\text { Western } \\
\text { Canada }\end{array}$ & $\begin{array}{l}\text { Cyrus } \\
\text { Reservoir, } \\
\text { UK }\end{array}$ & $\begin{array}{l}\text { Mansouri } \\
\text { Field, } \\
\text { Iran }\end{array}$ & $\begin{array}{l}\text { Pagerungan } \\
\text { Island, } \\
\text { Indonesia }\end{array}$ & $\begin{array}{c}\text { ABK } \\
\text { field, } \\
\text { Abu-Dhabi }\end{array}$ & $\begin{array}{l}\text { Offshore } \\
\text { Wells, } \\
\text { Arabian } \\
\text { Gulf }\end{array}$ & $\begin{array}{c}\text { Cusiana } \\
\text { Field, } \\
\text { Columbia }\end{array}$ & $\begin{array}{l}\text { Cusiana } \\
\text { Field, } \\
\text { Columbia }\end{array}$ \\
\hline Source & [4] & [5] & [6] & [7] & [8] & [9] & [10] & [11] \\
\hline $\begin{array}{c}\text { Andersonian } \\
\text { Type }\end{array}$ & Strike-slip & Extensional & Strike-slip & Strike-slip & Compression & naxtensional & Strike-slip & Strike-slip \\
\hline Depth (m) & $>3048$ & 2600 & 2313 & 1463-1890 & 2958 & 2073 & 4572 & 3048 \\
\hline $\begin{array}{c}\sigma_{V} \\
\text { gradient } \\
(\mathrm{kPa} / \mathrm{m})\end{array}$ & $24.9 \pm 0.7$ & 22.6 & 25.3 & 22.6 & 22.6 & 24.9 & 24.4 & 24.9 \\
\hline $\begin{array}{c}\sigma_{H} \\
\text { gradient } \\
(\mathrm{kPa} / \mathrm{m})\end{array}$ & 28.0 & 17.0 & 27.6 & 27.6 & 34.4 & 22.6 & 30.8 & 31.7 \\
\hline $\begin{array}{l}\sigma_{h} \text { gradient } \\
(\mathrm{kPa} / \mathrm{m})\end{array}$ & $19.2 \pm 1.4$ & 17.0 & 14.3 & 19.7 & 24.4 & 20.4 & 17.0 & 15.8 \\
\hline $\begin{array}{c}P_{p} \\
\text { gradient } \\
(\mathrm{kPa} / \mathrm{m})\end{array}$ & 9.7 & 10.2 & 9.3 & 10.2 & 10.2 & 10.4 & 9.5 & 10.0 \\
\hline $\begin{array}{r}\text { UCS } \\
(\mathrm{MPa})\end{array}$ & - & - & 27.8 & 47.7 & 5.5 & 21.3 & 70.0 & - \\
\hline $\begin{array}{c}\text { Cohesion } \\
\text { (MPa) }\end{array}$ & - & 5.9 & 5.4 & 12.4 & - & 6.0 & 19.8 & - \\
\hline $\begin{array}{l}\text { Tensile } \\
\text { Strength } \\
\text { (MPa) }\end{array}$ & - & - & 2.0 & - & - & - & - & - \\
\hline $\begin{array}{l}\text { Internal } \\
\text { Friction } \\
\text { Angle }\left({ }^{\circ}\right)\end{array}$ & - & 43.8 & - & 35.0 & 50.2 & 31.3 & 31.0 & - \\
\hline $\begin{array}{l}\text { Poisson's } \\
\text { Ratio }\end{array}$ & - & & 0.18 & 0.20 & 0.30 & & - & - \\
\hline
\end{tabular}

\subsection{Comparison of Failure Criteria}

One of the primary goals for a safe and stable drilling process is to maintain the wellbore pressure within the safe window by controlling the drilling fluid weight based on estimations of the pore pressure at depth. Since the calculated safe pressure range varies with the selected failure criteria, most prior studies focused on identifying the most appropriate criterion. In the present study, critical wellbore pressures are compared for four of the most common shear failure criteria (Mohr-Coulomb, Mogi-Coulomb, modified Lade, and the Drucker-Prager) using a range of in-situ stress conditions. The failure envelopes for each of the four criteria can be directly established with the Mohr-Coulomb 
parameters, such as cohesion and internal friction angle. For a concise review of the failure criteria, including equations and concepts, readers are referred to the supplementary online file.

Table 2. Input data for the three Andersonian cases.

\begin{tabular}{cccc}
\hline Andersonian Type & Compressional & Strike-Slip & Extensional \\
\hline$\sigma_{V}$ gradient $(\mathrm{kPa} / \mathrm{m})$ & 22.6 & 22.6 & 22.6 \\
\hline$\sigma_{H}$ gradient $(\mathrm{kPa} / \mathrm{m})$ & 29.4 & 24.9 & 20.4 \\
\hline$\sigma_{h}$ gradient $(\mathrm{kPa} / \mathrm{m})$ & 24.9 & 20.4 & 15.8 \\
\hline$\chi$ & 0.20 & 1.00 & 5.00 \\
\hline$P_{p}$ gradient $(\mathrm{kPa} / \mathrm{m})$ & & 10.2 & \\
\hline Cohesion $(\mathrm{MPa})$ & 6.9 & \\
\hline Internal Friction Angle $\left(^{\circ}\right)$ & 40.00 \\
\hline Unconfined Compressive Strength $(\mathrm{MPa})$ & 29.6 & \\
\hline Poisson's ratio & 0.25 &
\end{tabular}

Among the various rock failure criteria, the most frequently used during wellbore stability analysis is the Mohr-Coulomb failure criterion [12]. Despite of its wide area of application, many researchers pointed out that the 2D results may bias a wellbore stability analysis, because the criterion underestimates rock strengths by neglecting the effect of the intermediate principal stress [12-15]. The use of this failure criterion would result in too conservative and narrow safe drilling window, because of the unwarranted low rock strength assumption. Meanwhile, several studies proposed modifications of the criterion in an attempt to compensate the shortcomings [16,17].

Recently, the Mogi-Coulomb criterion gained attention in wellbore stability analysis, because it mitigates the defects of the Mohr-Coulomb criterion by taking into account the intermediate stress effect. Several studies suggest evidence that the criterion provides favorable results when compared with the laboratory and field scale analyses $[14,18,19]$.

A third failure criterion used in the present study is the modified Lade criterion proposed by Ewy [13]. The author performed experimental analyses and pointed out that the criterion shows reliable results for wellbore stability studies. However, Zhang, Cao, and Radha [19] insisted that the criterion is not suitable for estimation of the critical wellbore pressure at the lower-bound of the safe drilling window.

Additionally, the Drucker-Prager failure criterion was included in our study, because it ranks among the most widely used failure criteria in wellbore stability analysis [13]. There are three options for the Drucker-Prager constants, which result in the yield surface circumscribing, middle-inscribing or inscribing that of the Mohr-Coulomb criterion (Figure 1a). Based on field studies, McLean and Addis [5] concluded that the Drucker-Prager criterion favorably predicts the potential failure in wellbore stability analysis when the circumscribing constants are chosen. However, other studies indicated that the criterion overestimates the rock strength and may lead to unrealistic results with failure envelopes overstepping the safe drilling window [13]. 


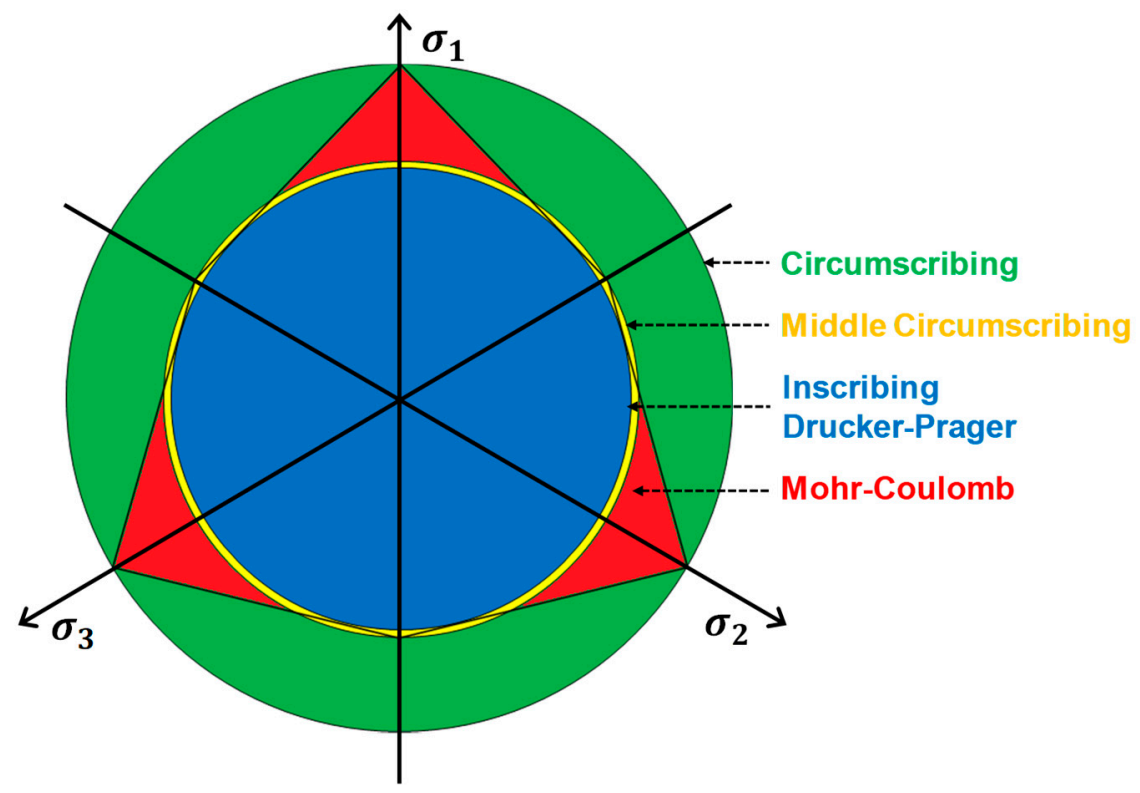

(a)

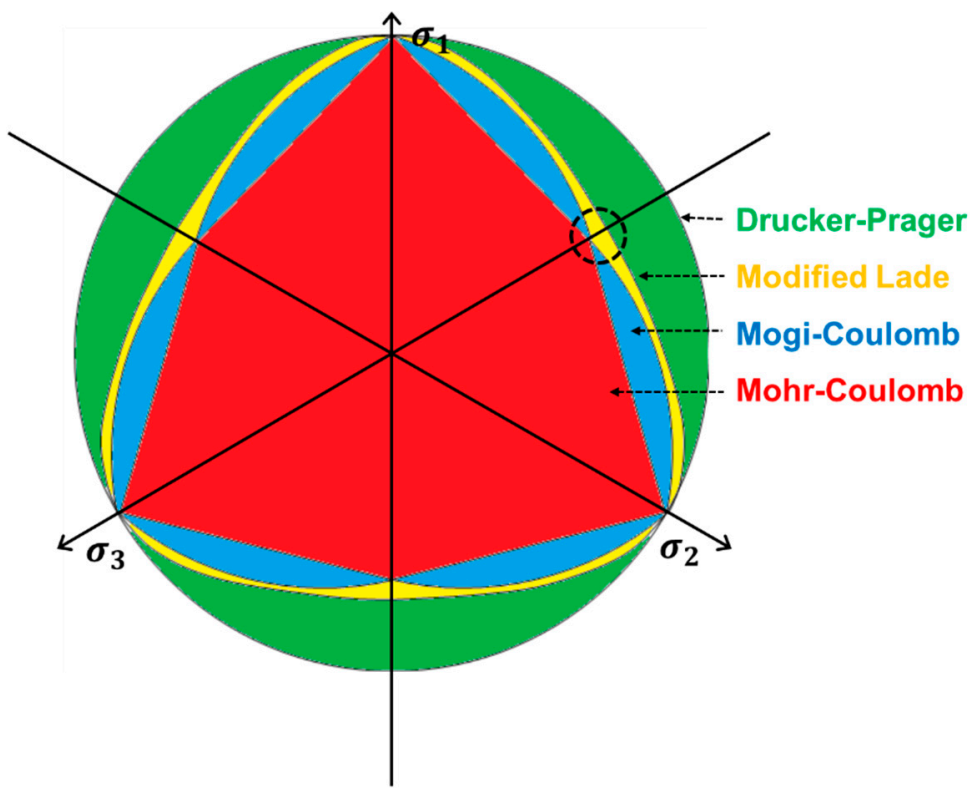

(b)

Figure 1. (a) Failure surfaces in $\pi$-plane calculated by the Drucker-Prager and Mohr-Coulomb failure criteria. The Drucker-Prager constants were determined with the assumptions that the failure surface circumscribes (green), middle circumscribes (yellow) or inscribes (blue) the failure surface of the Mohr-Coulomb (red) criterion. Internal friction angle is $30^{\circ}$. (b) Failure surfaces in $\pi$-plane calculated by the Drucker-Prager (circumscribing case, green), modified Lade (yellow), Mogi-Coulomb (blue), and Mohr-Coulomb (red) failure criteria. The dashed black circle represents the stress state where the maximum and intermediate principal stresses are identical. Internal friction angle is $30^{\circ}$.

In order to compare the results of the four failure criteria, their yield surfaces are depicted in the $\pi$-plane (Figure 1b). Readers should note that (only in Figure 1) the general relation of the principal stresses, $\sigma_{1} \geq \sigma_{2} \geq \sigma_{3}$, was abandoned for easy representation. A rock reaches failure when the stress state is placed at the edges of the shaded area. For the Drucker-Prager criterion, the constants of the circumscribing case were selected for our analysis. The result shows that the Drucker-Prager criterion has the widest yield surface (green), while the rock strengths calculated by the Mohr-Coulomb 
criterion are the most conservative (red). The failure surfaces determined by the Mogi-Coulomb (blue) and modified Lade (yellow) criteria are very similar and are slightly circumscribing the surface of the Mohr-Coulomb criterion. However, the largest discrepancy between the former criteria occurs when the two larger principal stresses have same magnitude, i.e., $\sigma_{1}=\sigma_{2}>\sigma_{3}$ (dashed black circle in Figure 1b). At this state, the minimum principal stress calculated by the Mogi-Coulomb criterion is higher than that of the modified Lade criterion. In addition, the yield surfaces determined by the Mohr-Coulomb and Mogi-Coulomb criteria are identical at this stress.

\section{Wellbore Stability Analysis Using Different Failure Criteria}

In this part of the study, the wellbore stability analysis is performed for a vertical well drilled into the three synthetic basins with Andersonian in-situ stress states using the Mohr-Coulomb, Mogi-Coulomb, modified Lade and Drucker-Prager failure criteria. For the Drucker-Prager criterion, the circumscribing case was chosen, which is identical to the Mohr-Coulomb and Mogi-Coulomb criteria under laboratory measurement conditions, i.e., $\sigma_{2}=\sigma_{3}$ For the same condition, the circumscribing Drucker-Prager criterion coincides with the modified Lade criterion as the latter was intentionally designed accordingly [20]. The Mohr-Coulomb, Mogi-Coulomb, modified Lade and Drucker-Prager criteria are widely used and the required parameters can be directly determined from the rock's cohesion and internal friction angle. Since usage of different criteria yields distinct results, many studies have been performed to analyze the physical nature and variations in strength of each particular failure criterion. Prior studies compared the various failure criteria using observations made by experimental $[13,18,19]$ and computational [21] methods, and concluded that the failure criteria are very sensitive to the 3D state of the stress. Furthermore, field evidence suggests that the effect of the intermediate principal stress is significant for any wellbore stability analysis [14,15,22-24].

The vertical well analyzed is assumed to be drilled in a thick formation for the reverse faulting, strike-slip and normal faulting cases, and a wellbore stability analysis needs to identify and calculate the lower and upper critical wellbore pressures, considering shear and tensile failure modes. The derivation of the equations required for the critical wellbore pressure calculations are described in the supplementary file. Combining the determined safe mud window with the pore pressure, potential near-wellbore damage is also analyzed. In addition, the principal stress condition at the location of the failure is closely examined to further investigate its effect on the calculated critical wellbore pressures. Previous studies focused on the selection of the appropriate failure criterion comparing their different outcomes. A systematic study of failure response for a broad range of possible stress states is undertaken in this study for the first time.

\subsection{Compressional Basin (Reverse Faulting) Case}

The critical wellbore pressures for the compressional basin case (Tables 2 and 3) are shown in Figure 2. The colored dashed lines represent the lower critical wellbore pressure that induces lower-bound shear failure at the wellbore wall at $\theta=\pi / 2$ or $3 \pi / 2$. Whether failure at the upper-bound is by shear or tensile failure (expected at $\theta=0$ or $\pi$ ) depends on depth as indicated by the solid lines (black for tensile and colored for upper-bound shear failure). The lines for upper-bound shear failure are dotted where tensile failure will prevail. Tensile failure will occur at shallower depths $(<1188 \mathrm{~m})$ and consequently shear failure is less likely to occur due to tensile failure releasing the stress accumulations. However, the deeper wellbore section $(>1188 \mathrm{~m})$ is more prone to failure by shear at the upper-bound, which occurs at a critical pressure lower than required for tensile failure (Figure 2). The $1188 \mathrm{~m}$ depth for the transition between upper-bound tensile failure and shear failure is only valid for the Mohr-Coulomb shear failure criterion. For other shear failure criteria, tensile failure still prevails for the deeper well sections (see later). 
Table 3. Conversion of wellbore principal stress subscript system $\left(\sigma_{H}, \sigma_{h}, \sigma_{V}\right)$ to conventional principal stress system $\left(\sigma_{1}, \sigma_{2}, \sigma_{3}\right)$ depending on tectonic stress regime.

\begin{tabular}{cccc}
\hline Andersonian Case & \multicolumn{3}{c}{ Spatially Fixed Subscripts } \\
\hline Compressional Basin & $\sigma_{H}$ & $\sigma_{h}$ & $\sigma_{V}$ \\
\hline Extensional Basin & $\sigma_{V}$ & $\sigma_{H}$ & $\sigma_{h}$ \\
\hline Strike Slip Basin & $\sigma_{H}$ & $\sigma_{V}$ & $\sigma_{h}$ \\
\hline Principal Total Stress Subscripts (all cases) & $\sigma_{1}$ & $\sigma_{2}$ & $\sigma_{3}$ \\
\hline Principal Deviatoric Stress Subscripts (all cases) & $\tau_{1}$ & $\tau_{2}$ & $\tau_{3}$ \\
\hline
\end{tabular}

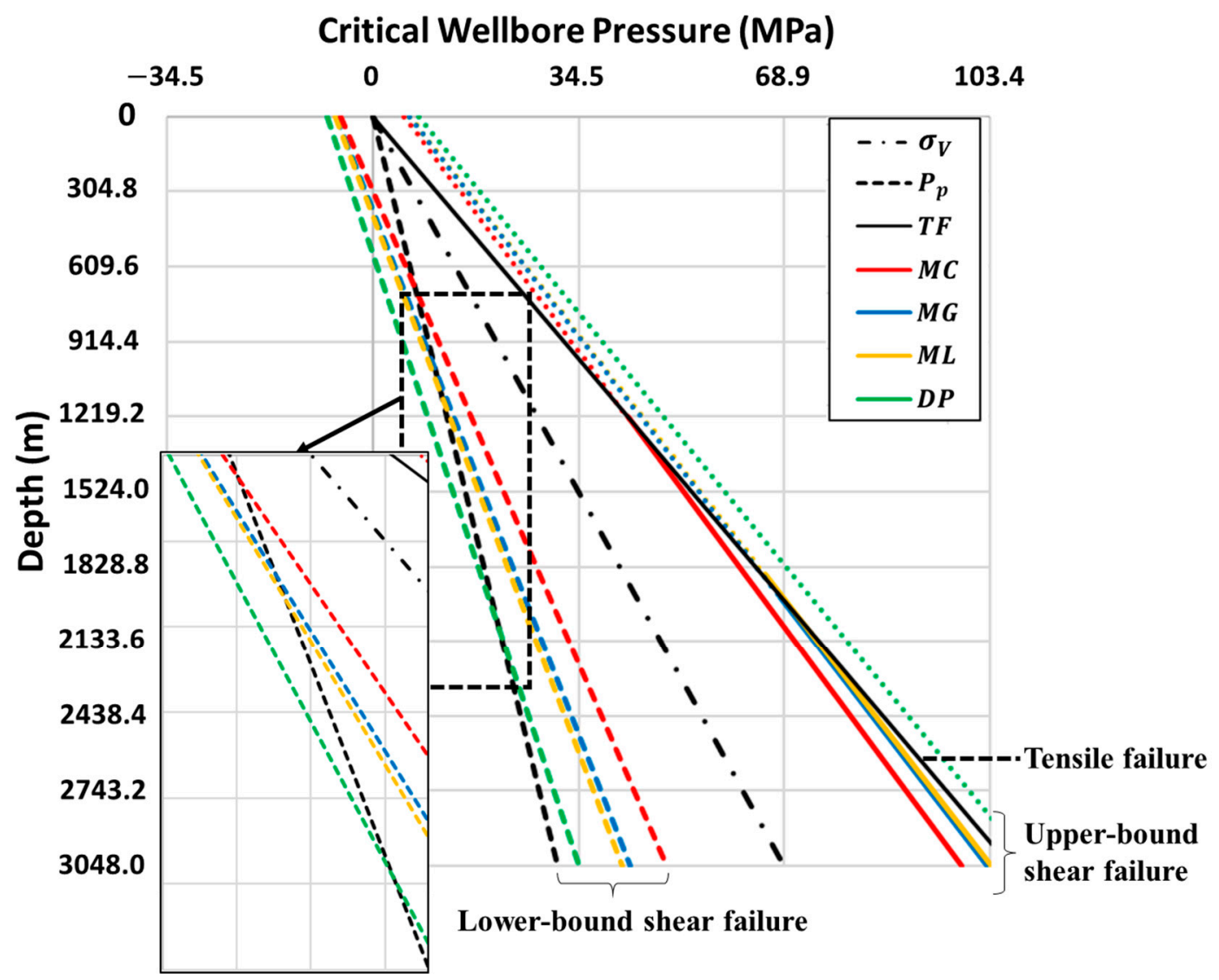

Figure 2. Reverse faulting regime - compressional basin. Critical wellbore pressure at lower- (colored dashed), upper-bound shear (colored solid), and tensile (TF; black solid) failures under the reverse faulting regime with the vertical, maximum and minimum horizontal stress gradients of 22.6, 29.4, and $24.9 \mathrm{kPa} / \mathrm{m}$, respectively. The pore pressure gradient is $10.2 \mathrm{kPa} / \mathrm{m}$ (black dashed). The wellbore pressures were calculated by the Mohr-Coulomb (MC; red), Mogi-Coulomb (MG; blue), modified Lade (ML; yellow), and Drucker-Prager (DP; green) failure criteria. The vertical in-situ stress is depicted with the dash-dotted black line. The magnified frame indicates that the calculated lower critical wellbore pressures exceed the pore pressure at certain depths. Input parameters are given in Tables 2 and 3.

The wellbore pressure needs to be maintained between the dashed and solid lines (Figure 2) to ensure a safe and stable drilling process. The critical wellbore pressures were calculated using the Mohr-Coulomb (red), Mogi-Coulomb (blue), modified Lade (yellow), and Drucker-Prager (green) failure criteria. The black dash-dotted and dashed lines represent, respectively, the minimum in-situ stress gradient $(22.6 \mathrm{kPa} / \mathrm{m})$ and the pore pressure gradient $(10.2 \mathrm{kPa} / \mathrm{m})$ along the vertical wellbore trajectory. The magnitude and gradient of the minimum in-situ stress (which is vertical for the compressional basin), is very important for the analysis, because a hydraulically-driven tensile fracture 
will only propagate away from the wellbore wall if the wellbore pressure exceeds the minimum in-situ stress. The safe mud window determined by the Drucker-Prager criterion has the widest range, while the window calculated by the Mohr-Coulomb criterion is the narrowest for the entire interval. The critical wellbore pressure window obtained from Mogi-Coulomb is slightly narrower than that of the modified Lade.

Figure 2 includes the transition depths where the calculated critical pressure for a certain shear failure criterion is no longer valid (dotted lines). Tensile failure is the most likely type of the failure to occur at shallower depths for all criteria. The critical pressures and corresponding depths of the tensile-shear failure transition are included in Figure 2 for each shear failure criterion. As the well penetrates deeper formations, tensile failure is less likely to occur than upper-bound shear failure. Deeper in the wellbore the critical pressure for tensile failure would need to be higher than for shear failure. Tensile failure is expected at the upper-bound of the critical wellbore pressure window for well depths shallower than 1188 (Mohr-Coulomb), 1862 (Mogi-Coulomb), and 1998 m (Modified Lade). According to the Drucker-Prager criterion, however, the upper-bound shear failure cannot occur even when a well reaches $3048 \mathrm{~m}$ depth. Consequently, upper-bound shear failure is generally more likely to occur at the greater depths (instead of tensile failure) if the wellbore pressure reaches the upper critical wellbore pressure.

Figure 2 also shows that the pore pressure line cuts across the calculated lower critical wellbore pressure. In other words, the pore pressure becomes lower than the critical wellbore pressure at lower-bound shear failure when a well gets deeper. Since the wellbore pressure needs to be maintained higher than the dashed lines for the stability, the desirable wellbore pressure will be higher than the formation pore pressure. For such cases, the wellbore pressure needs to be significantly overbalancing the pore pressure at depths of 622,911, 1001 and $1640 \mathrm{~m}$, according to the Mohr-Coulomb, Mogi-Coulomb, modified Lade and the Drucker-Prager criteria, respectively (see also magnified frame in Figure 2, Table 4). The risk of loss of costly drilling mud increases with depth. Remediation requires properly designed drilling fluid to create an impermeable mud cake at the wellbore wall to prevent any mud loss to the formation. Additional caution needs to be taken when natural fractures occur, which may be difficult to plug with standard drilling fluid. When formations are naturally fractured (prior to drilling), mud loss will be more likely to occur at greater depths.

Table 4. Depths at the positive net pressure required to prevent shear failure.

\begin{tabular}{cccc}
\hline Andersonian Type & Compressional (m) & Strike-Slip (m) & Extensional (m) \\
\hline Mohr-Coulomb & 688 & 872 & 1188 \\
\hline Mogi-Coulomb & 1035 & 1379 & 1862 \\
\hline Modified Lade & 1128 & 1470 & 2002 \\
\hline Drucker-Prager & 2109 & - & - \\
\hline
\end{tabular}

When calculating the critical wellbore pressure with the selected failure criteria, the locally induced principal stress condition at wellbore wall is calculated using the Kirsch equations and integrated with the failure criteria. In order to closely investigate behavior of the critical wellbore pressure, the principal stress condition at the failure location was further analyzed for the lower-bound shear failure (at $\theta=\pi / 2$ or $3 \pi / 2$ ), and upper-bound shear failure (at $\theta=0$ or $\pi$ ). Figure $3 a$,b show the radial and tangential stresses at the lower-bound and upper-bound shear failure locations, respectively. For both cases, the axial stress $\left(\sigma_{z}\right)$ is represented with a black solid line as it is a function of the in-situ stresses and Poisson's ratio (See the supplementary file)). The tangential (solid; $\sigma_{\theta}$ ) and radial (dashed; $\left.\sigma_{r}\right)$ stresses depend on the wellbore pressure and vary with the failure criteria. At the location of the lower-bound shear failure, the tangential and radial (near wellbore) stresses are the maximum and minimum principal stresses for the entire depth, respectively. On the other hand, the tangential and radial (near wellbore) stresses are the minimum and maximum principal stresses at upper-bound shear 
failure location, respectively. For both failure locations, the axial stress is the intermediate principal stress. For the reverse faulting case, the order of the principal stresses remains consistent in vertical wells up to $3048 \mathrm{~m}$ deep.

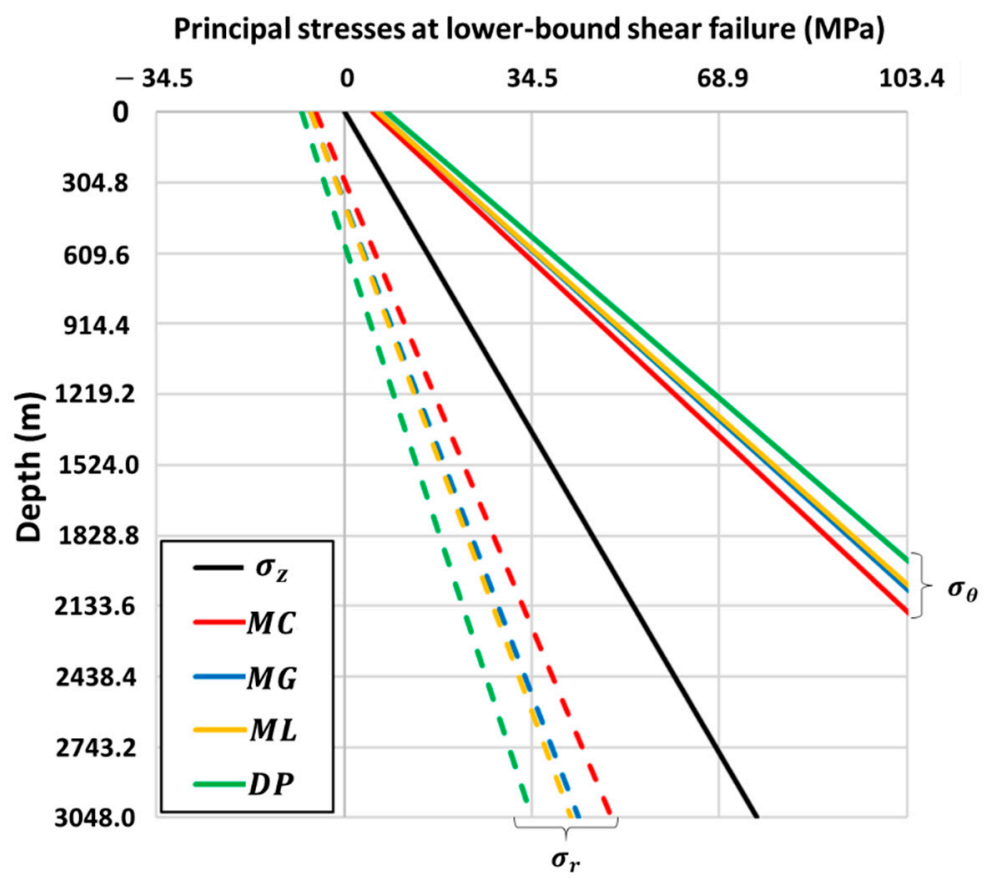

(a)

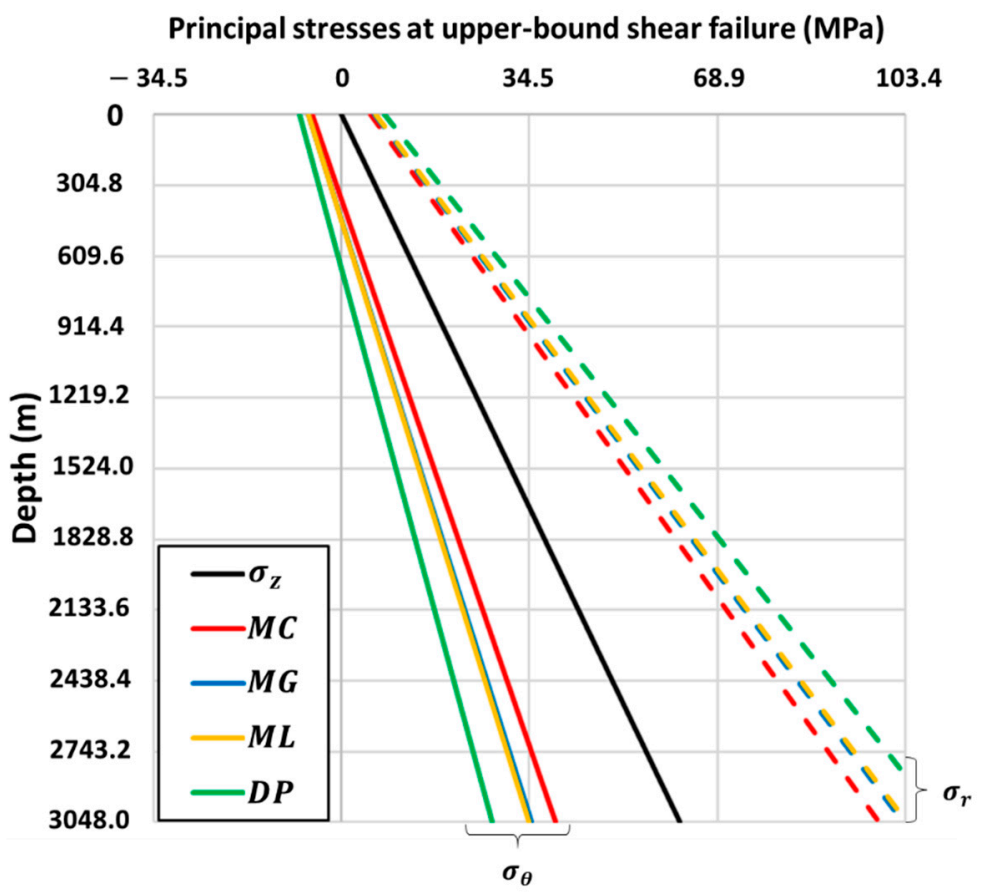

(b)

Figure 3. Reverse faulting regime-compressional basin. Locally induced principal stresses at a moment of (a) lower-bound and (b) upper-bound shear failure under the reverse faulting regime with the vertical, maximum and minimum horizontal stresses of $22.6,29.4$, and $24.9 \mathrm{kPa} / \mathrm{m}$, respectively. The black solid lines represent the axial stress $\left(\sigma_{z}\right)$. The tangential $\left(\sigma_{\theta} ;\right.$ solid $)$ and radial $\left(\sigma_{r} ;\right.$ dashed) stresses are calculated by the Mohr-Coulomb (MC; red), Mogi-Coulomb (MG; blue), modified Lade (ML; yellow), and Drucker-Prager (DP; green) failure criteria. 


\subsection{Strike-Slip Basin Case}

Figure 4 shows the calculated critical wellbore pressure for the strike-slip basin case. Similar to the observations from the compressional basin case (Figure 2), the Drucker-Prager criterion estimates the widest safe window of the drilling fluid weight and the Mohr-Coulomb criterion yields the most conservative result. The magnified inset frame in Figure 4 indicates that the lower critical wellbore pressures for shear failure at the lower-bound are higher than the pore pressure at depths greater than 871, 1379, and $1470 \mathrm{~m}$, based on the Mohr-Coulomb, Mogi-Coulomb and modified Lade shear failure criteria (Table 4). Beyond these depths, the wellbore pressure needs to be maintained higher than the pore pressure to prevent shear failure. However, if the formation rock follows the Drucker-Prager criterion, even an underbalanced wellbore pressure can still provide stability. The interval where the wellbore pressure must exceed the formation pore pressure to prevent shear failure according to the three conservative criteria (Mohr-Coulomb, Mogi-Coulomb and modified Lade) (Figure 4) generally occurs deeper than for the reverse faulting case (Figure 2).

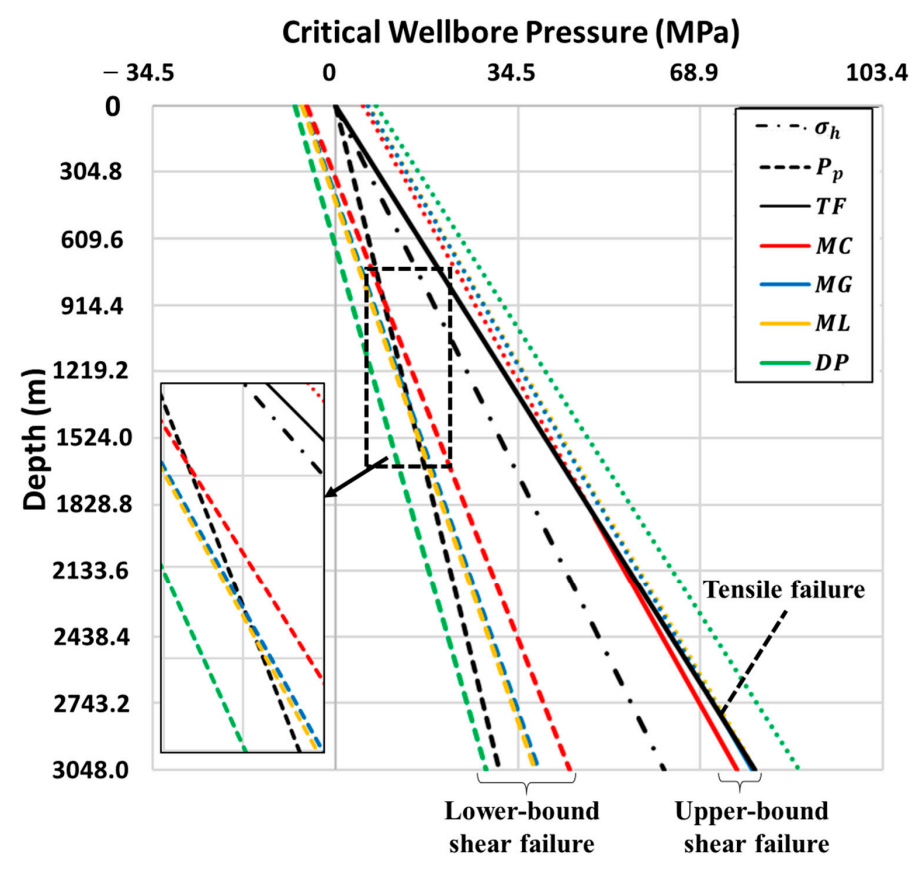

Figure 4. Strike-slip regime-strike-slip basin. Critical wellbore pressure at lower- (colored dashed), upper-bound shear (colored solid), and tensile (TF; black solid) failures under the strike-slip regime with the vertical, maximum and minimum horizontal stress gradients of $22.6,24.9$, and $20.4 \mathrm{kPa} / \mathrm{m}$, respectively. The pore pressure gradient is $10.2 \mathrm{kPa} / \mathrm{m}$ (black dashed). The wellbore pressures were calculated by the Mohr-Coulomb (MC; red), Mogi-Coulomb (MG; blue), modified Lade (ML; yellow), and Drucker-Prager (DP; green) failure criteria. The minimum horizontal in-situ stress is depicted with the dash-dotted black line. The magnified frame indicates that the calculated lower critical wellbore pressures exceed the pore pressure at certain depths.

At the upper-bound of the safe wellbore pressure window, tensile failure is more likely to occur than shear failure for well depths shallower than 1868 and $2840 \mathrm{~m}$, according to the Mohr-Coulomb and Mogi-Coulomb criteria, respectively. However, the results from the modified Lade and the Drucker-Prager criteria show that the tensile failure will occur up to $3048 \mathrm{~m}$ (instead of the upper-bound shear failure), which would require higher wellbore pressure.

Figure $5 \mathrm{a}, \mathrm{b}$ show the radial, axial and tangential stresses at the lower-bound and upper-bound shear failure locations. Like the reverse faulting case (Figure 3), the tangential and radial stresses are the maximum and minimum principal stresses at the locations of lower-bound shear failure (Figure 4). The vertical stress is the intermediate principal stress, and the order of the principal stresses retain the 
same orientation with respect to the wellbore and are consistent with a compressional tectonic regime over the entire interval at both the upper and lower-bound failure locations.

Principal stresses at lower-bound shear failure (MPa)

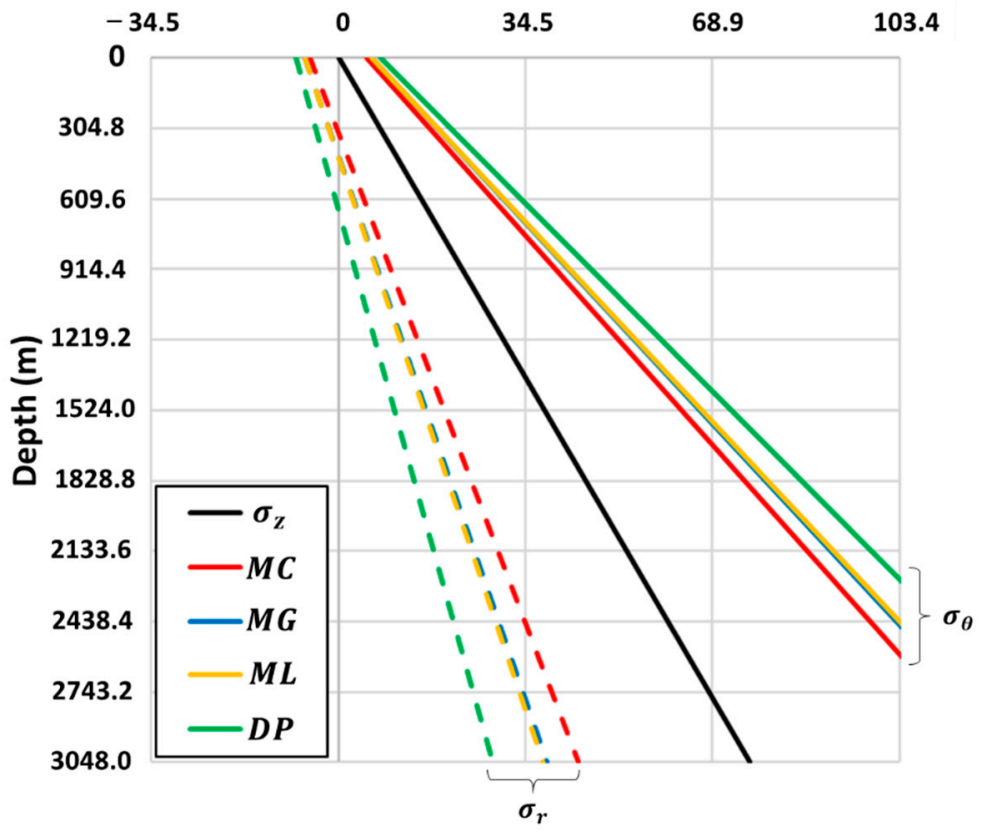

(a)

Principal stresses at upper-bound shear failure (MPa)

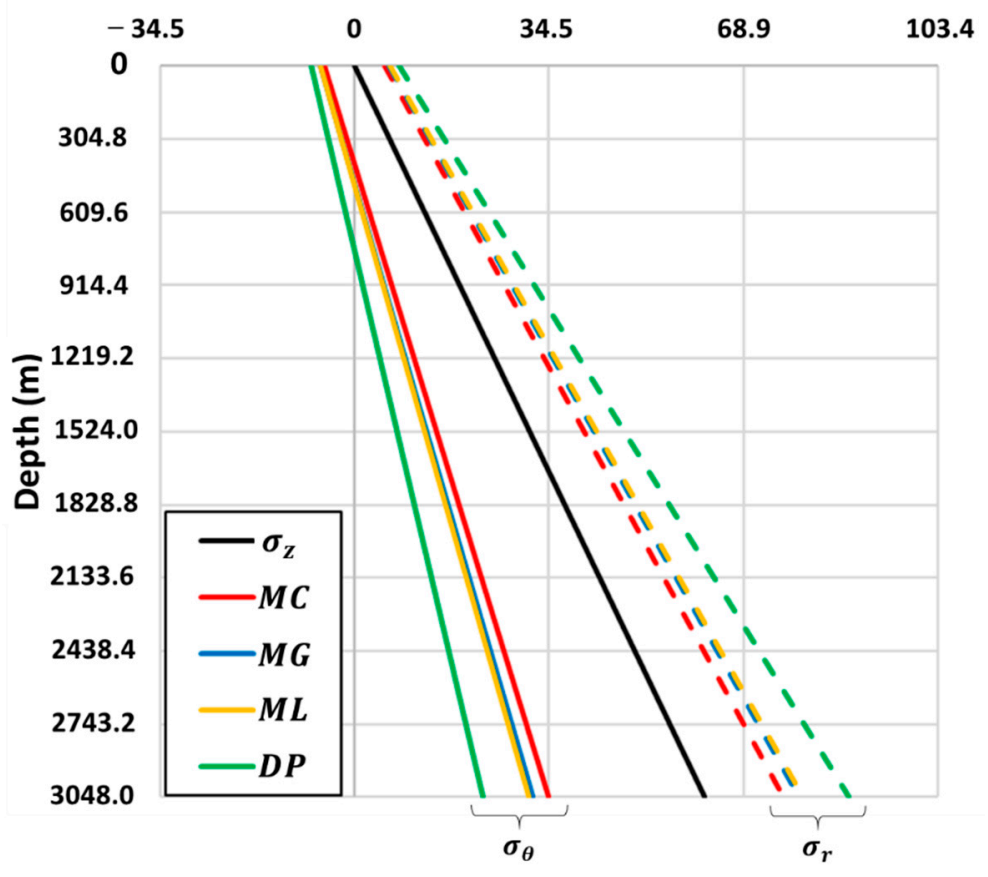

(b)

Figure 5. Strike-slip regime-strike-slip basin. Locally induced principal stresses at a moment of (a) lower-bound and (b) upper-bound shear failure under the strike-slip regime with the vertical, maximum and minimum horizontal stresses of $22.6,24.9$, and $20.4 \mathrm{kPa} / \mathrm{m}$, respectively. The black solid lines represent the axial stress $\left(\sigma_{z}\right)$. The tangential $\left(\sigma_{\theta} ;\right.$ solid) and radial $\left(\sigma_{r} ;\right.$ dashed) stresses are calculated by the Mohr-Coulomb (MC; red), Mogi-Coulomb (MG; blue), modified Lade (ML; yellow), and Drucker-Prager (DP; green) failure criteria. 


\subsection{Extensional Basin (Normal Faulting) Case}

Figure 6 shows the critical wellbore pressure at shear and tensile failures for the extensional basin case. In accordance with the calculated safe windows of the other two cases of Andersonian tectonics (Figures 2 and 4), the safe drilling windows calculated by the Drucker-Prager and Mohr-Coulomb criteria again have the widest and narrowest widths (Figure 6), respectively. The result from the Mohr-Coulomb criterion shows that the upper-bound shear failure is expected for the wellbore pressure exceeding the critical pressure at depth greater than $2905 \mathrm{~m}$. For the other shear failure criteria, tensile failure will be more likely to occur than shear failure for the entire $3048 \mathrm{~m}$ deep well. As the dashed lines in Figure 6 indicate, the critical wellbore pressure at the lower-bound of the safe window is lower than the pore pressure at specific depths. According to the Mohr-Coulomb, Mogi-Coulomb and modified Lade criteria, the shear failure can occur even when the wellbore is maintained over-balanced at a depth greater than 1188, 1864, or 2002 m (magnified frame (a) in Figure 6). However, the result from the Drucker-Prager criterion shows that shear failure can be prevented at all depths up to $3048 \mathrm{~m}$ deep, even when the wellbore fluid pressure is lower (underbalanced) than the pore pressure. Compared to the other Andersonian cases (Figures 2 and 4), the interval that requires higher wellbore pressure than the pore pressure is located at deeper formations for the extensional basin (Table 4). Our conclusion is that the normal faulting case is the Andersonian case with the deepest intervals requiring overbalanced drilling to support wellbore stability.

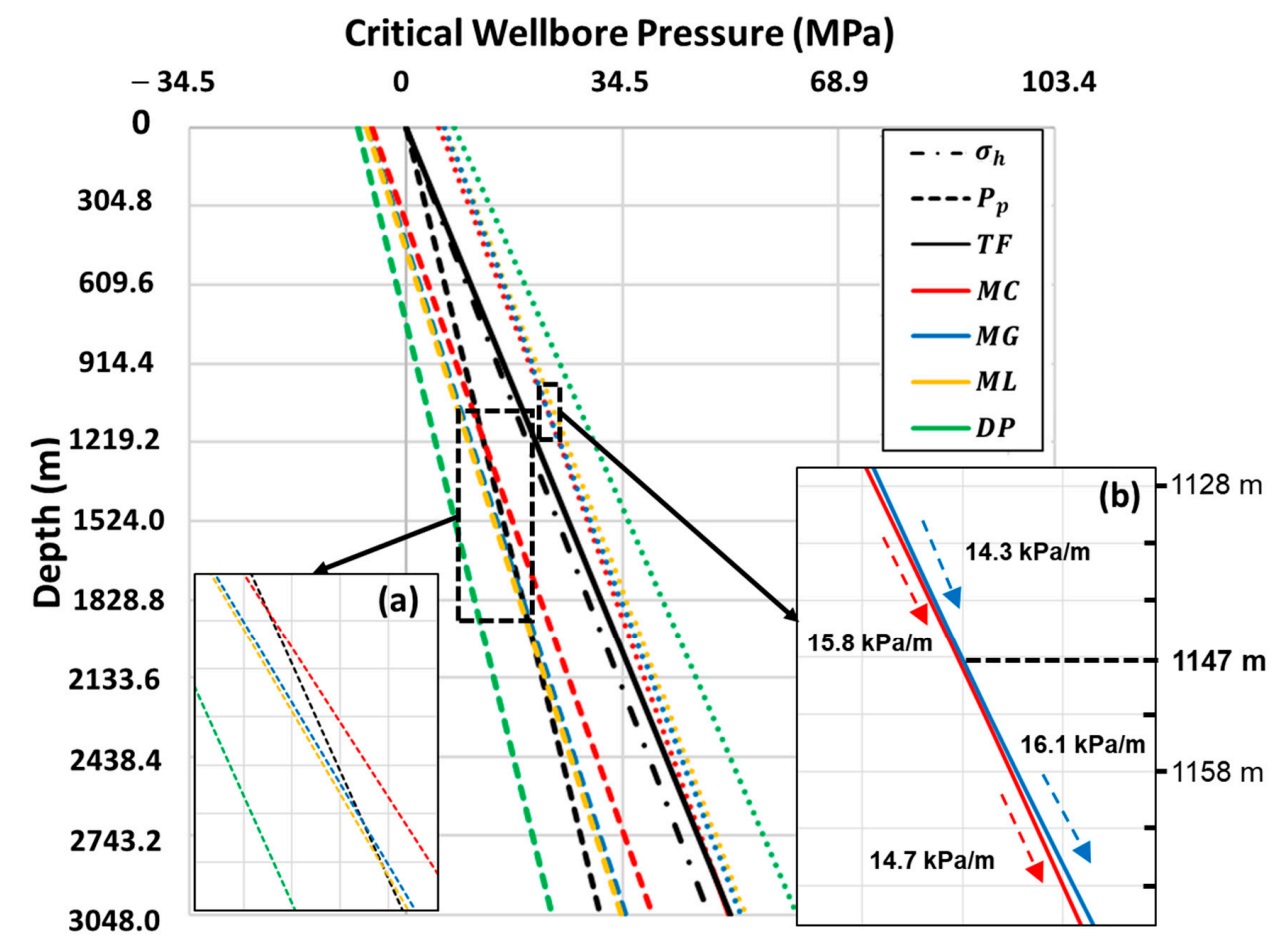

Figure 6. Normal faulting regime-extensional basin. Critical wellbore pressure at lower- (colored dashed), upper-bound shear (colored solid), and tensile (TF; black solid) failures under the normal faulting case with the vertical, maximum and minimum horizontal stress gradients of 22.6, 20.4, and $15.8 \mathrm{kPa} / \mathrm{m}$, respectively. The pore pressure gradient is $10.2 \mathrm{kPa} / \mathrm{m}$ (black dashed). The wellbore pressures were calculated by the Mohr-Coulomb (MC; red), Mogi-Coulomb (MG; blue), modified Lade (ML; yellow), and Drucker-Prager (DP; green) failure criteria. The minimum horizontal in-situ stress is depicted with the dash-dotted black line. The magnified frame (a) indicates that the calculated lower critical wellbore pressures exceed the pore pressure at certain depths. The magnified frame (b) shows the alteration of the upper critical wellbore pressure gradient calculated by the Mohr-Coulomb (red) and Mogi-Coulomb (blue) criteria. 
At upper-bound of the critical pressure window, shear failure gradients calculated by the Mohr-Coulomb and Mogi-Coulomb criteria show a sudden change in slope at $1147 \mathrm{~m}$ depth (inset (b) of Figure 6). We recall that the upper-bound shear failure gradients for the other two Andersonian cases (Figures 2 and 4) remained constant or only gradually changed. As the magnified frame (b) in Figure 6 shows, the upper critical wellbore pressure gradients calculated by the Mohr-Coulomb and Mogi-Coulomb criteria at $1147 \mathrm{~m}$ change from 15.8 and $14.3 \mathrm{kPa} / \mathrm{m}$ to 14.7 and $16.1 \mathrm{kPa} / \mathrm{m}$, respectively.

In order to further unearth the cause of the abrupt change in the shear failure gradient, the locally induced stresses at the failure points were analyzed (Figure 7a,b). As for the other Andersonian cases (Figures 3 and 5), the tangential, axial and radial stresses are the maximum, intermediate and minimum principal stresses. The principal stress order at the lower-bound shear failure envelope $(\theta=\pi / 2$ or $3 \pi / 2$ ) remains consistent for the entire drilling interval (Figure 7a). However, the principal stress condition at the upper-bound shear failure location, $\theta=0$ or $\pi$ (magnified in Figure $7 \mathrm{~b}$ ) shows that the axial stress becomes the intermediate principal stress at shallow depth (instead of the radial stress). Consequently, the order of the principal stresses at the upper-bound shear failure location reverses from $\sigma_{r}>\sigma_{z}>\sigma_{\theta}$ to $\sigma_{z}>\sigma_{r}>\sigma_{\theta}$ at exactly the depth where the shear failure gradient changes slope. The principal stress order reversals occur at depths of 1147 (Mohr-Coulomb), 1147 (Mogi-Coulomb), and $1367 \mathrm{~m}$ (modified Lade), see red circles in the magnified frame of Figure $7 \mathrm{~b}$.

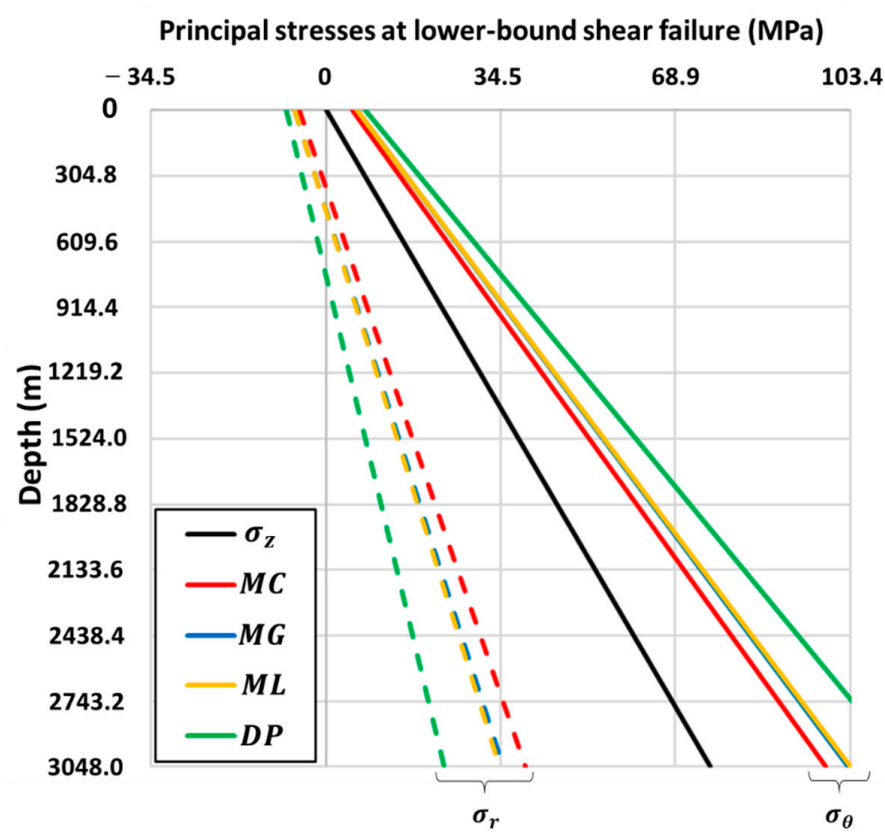

(a)

Figure 7. Normal faulting regime. Locally induced principal stresses at a moment of (a) lower-bound and (b) upper-bound shear failure under the normal faulting regime with the vertical, maximum and minimum horizontal stresses of $22.6,20.4$, and $15.8 \mathrm{kPa} / \mathrm{m}$, respectively. The black solid lines represent the axial stress $\left(\sigma_{z}\right)$. The tangential $\left(\sigma_{\theta} ;\right.$ solid) and radial $\left(\sigma_{r} ;\right.$ dashed) stresses are calculated by the Mohr-Coulomb (MC; red), Mogi-Coulomb (MG; blue), modified Lade (ML; yellow), and Drucker-Prager (DP; green) failure criteria. The magnified frame in $(b)$ indicate reverse of the principal stress order. (c) Critical wellbore pressure difference at upper-bound shear failure. Difference between the Mohr-Coulomb (MC) and Mogi-Coulomb (MG), and the Mogi-Coulomb and modified Lade (ML) are shown in red and yellow curves, respectively. At $1147 \mathrm{~m}$, the red curve reaches 0 and the yellow curve shows the maximum value. 


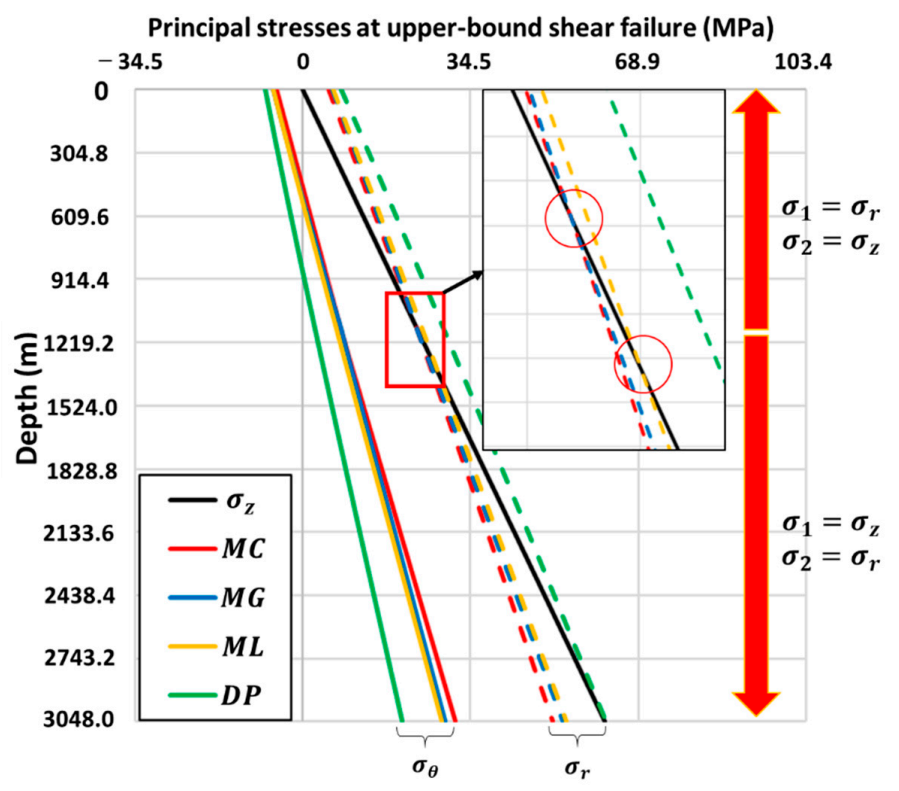

(b)

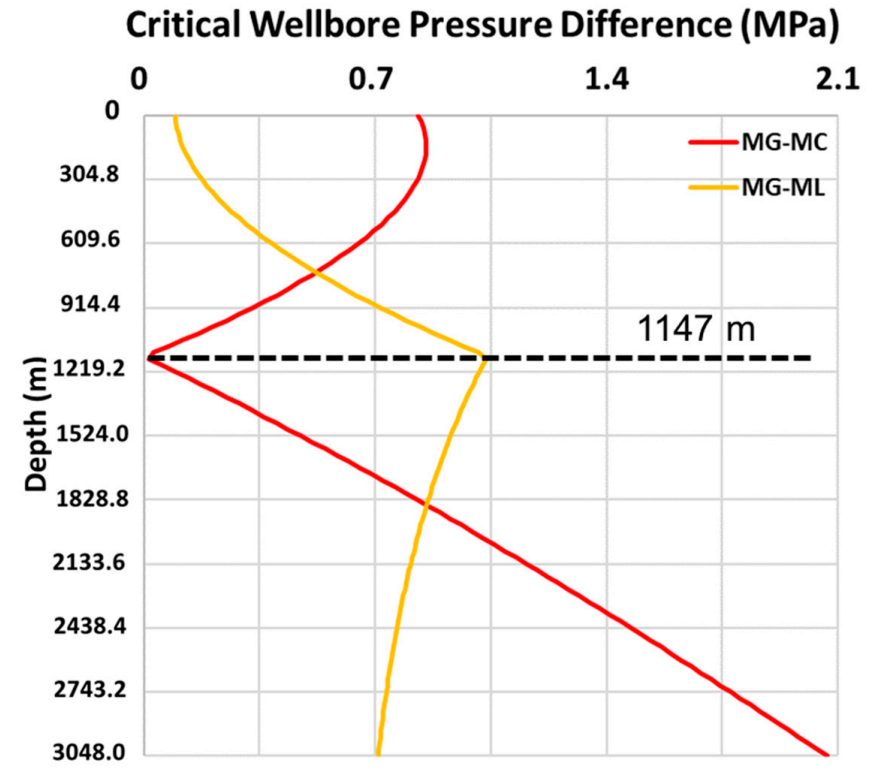

(c)

Figure 7. Cont.

Since the Mohr-Coulomb and Mogi-Coulomb criteria take into account the order of the principal stresses in critical wellbore pressure calculation, the gradients show a sudden alteration at the depths where the principal stress order reverses. However, such a reversal does not have an influence on the critical wellbore pressure gradient calculated by the modified Lade criterion as the criterion does not take into account the order of the principal stresses. The difference between the critical wellbore pressures at the upper-bound calculated from the Mogi-Coulomb and modified Lade criteria is maximum at $1147 \mathrm{~m}$ depth (yellow curve in Figure 7c). As described in Section 2.2, the stress states at failure of the Mogi-Coulomb and modified Lade are slightly different, except when the two larger principal stresses have the same magnitudes (dashed circle in Figure 1b). In addition, the upper critical wellbore pressure determined by the Mohr-Coulomb and Mogi-Coulomb criteria are identical as the magnitudes of the intermediate principal stress are equal to the maximum principal stress (red curve in Figure 7c), where the effect of the intermediate principal stress is negligible $\left(\sigma_{2}=\sigma_{3}\right)$. 


\section{Wellbore Stability Model Expanded with Principal Stress Trajectories and Deviatoric Stress Magnitude Contours}

In the second part of this study, both the deviatoric stress magnitudes and stress trajectories around the wellbore are determined at every depth for each of the three Andersonian cases at the margins of the safe drilling envelope. The method is based on Weijermars [25], who first advocated simply using deviatoric stresses $\left(\tau_{i j}\right)$ (rather than total stress, $\left.\sigma_{i j}\right)$ to determine the redistributed stress conditions around the wellbore. The advantage of taking out the confining pressure term (using $\tau_{i j}=\sigma_{i j}-P$ ), which has a magnitude equal to the scalar value of the mean stress, is that even when $P$ changes with depth, the deviatoric stresses and critical trajectories at the moment of failure (as separately quantified by applying a range of failure criteria, applying total stress) can be directly compared. The stress trajectory analysis, practical for predicting the potential failure locations and fracture propagation directions [26], is based on the Kirsch equations, and assumes the wellbore remains parallel to one of the principal stress axes, such that the other two principal stress axes act in the plane of the stress trajectories studied.

Rather than working with the dimensional values of the resulting radial and tangential stresses $\left(\tau_{r}, \tau_{\theta}\right)$, obtained by solving the Kirsch equations, a prior study [1] introduced two normalization parameters, essentially non-dimensionalizing $\left(\tau_{r}, \tau_{\theta}\right)$ by one of the two principal deviatoric stresses acting in the plane of study. To achieve the required non-dimensionalization, two dimensionless scaling factors $(X, F)$ were introduced (see details in Appendix A of Thomas and Weijermars [1]) each accounting for key terms in the Kirsch equations.

One scaling factor, coined the Bi-axial Stress scalar $(\chi)$ [1], scales the relative magnitude of the two far-field (deviatoric) stresses in the plane of study:

$$
\chi_{i}=\frac{-\tau_{k}}{\left|\tau_{j}\right|}
$$

The subscripts $i, j$ and $k$ differ for the compressional, strike-slip and extensional basins, with $i$ indicating the direction of the wellbore, and $j$ and $k$ are the maximum and minimum principal stress axes in the plane of study, i.e., normal to the wellbore. For example, a vertical wellbore in compressional, strike-slip and extensional basins, will have the indices $(i, j, k)$ as follows: $(3,1,2),(2,1,3)$, and $(1,2,3)$, respectively. When the wellbore is horizontal, the indices switch accordingly (see details in Appendix B and summary in Table A1).

The other scaling factor, coined the Frac number $(F)$ [2], scales the net pressure $\left(P_{N E T}\right)$ on the wellbore via normalization by the same far-field stress as is used in the denominator of $\chi_{i}$ :

$$
F_{i}=\frac{P_{N E T}}{\left|\tau_{j}\right|}
$$

where, $P_{N E T}$ is the difference between the internal wellbore pressure and the formation pore pressure, i.e., $P_{w}-P_{p}$. The subscript $i$ indicates the principal stress that the wellbore is aligned with. For a vertical wellbore, the subscript $i$ in the compressional, strike-slip and extensional basins is either 3,2, or 1 , respectively (see also Table A1). All possible states of deviatoric stress can be scaled by $(\chi, F)$ pairs and stress magnitude and trajectory contour plots only depend on these scaling factors. Appendices $B$ and $C$ provide detailed information about the dimensionless variables $(\chi, F)$ expressed in both total and deviatoric stress forms.

One should note that the radial and tangential stresses $\left(\tau_{r}, \tau_{\theta}\right)$ near the wellbore, and the local principal stress magnitudes derived thereof by applying the standard expression (Appendix C.2), are all normalized by the selected far-field deviatoric stress $\tau_{j}$ normal to the wellbore. Therefore, the absolute deviatoric stress magnitudes in each location can be obtained by multiplication with the same far-field stress $\tau_{j}$. Meanwhile, it is not necessary to put additional effort in differentiating the total and deviatoric stress trajectories as these remain identical for both the total and deviatoric stresses. The 
magnitude of the dimensional deviatoric stress in each location can be translated to the total stress by adding back in the dimensional confining pressure component $\left(\tau_{i j}=\sigma_{i j}+P\right)$.

With the above conventions in place, we now proceed to develop an alternative way to represent the safe drilling window by specifying the values of $(\chi, F)$ pairs at each depth for the critical wellbore pressure. The added advantage is that one will know the corresponding stress trajectory patterns at the moment of failure. The stress patterns will change with depth, in our examples gradually, but not necessarily so when formation properties change abruptly, such as the far-field stress magnitude varying at each depth due to differences in the elastic constants of each formation. Examples of the application of our new method are given using the same three synthetic, Andersonian cases used in the evaluation of failure criteria with the classical safe drilling window presentation in Section 3. This approach ensures we can compare and combine the two approaches as each have their own merits.

\subsection{Compressional Basin Case}

Figure 8 a shows the critical $F_{3}$ values at shear and tensile failures for the reverse faulting case. Such a reverse faulting regime corresponds to a compressional basin case, where typically the maximum $\left(\sigma_{1}\right)$, intermediate $\left(\sigma_{2}\right)$, and minimum $\left(\sigma_{3}\right)$ principal in-situ stresses are the maximum and minimum horizontal stresses $\left(\sigma_{H}\right.$ and $\left.\sigma_{h}\right)$ and the vertical stress $\left(\sigma_{V}\right)$, respectively. Using $\left(\sigma_{H}, \sigma_{h}, \sigma_{V}\right)$ values from Table 2, the $F_{3}$ and $\chi_{3}$ values can be calculated using the simple equations at the bottom row in Table A1, assumes a vertical wellbore aligned with the minimum principal in-situ stress, $\sigma_{3}$. The $\chi_{i}$-value can be used later to compute the stress distribution around the wellbore (Appendix C).

The $F$ values are the net pressure on the wellbore, normalized by the maximum principal deviatoric stress $\left(\tau_{1}\right)$ For the compressional basin $\sigma_{1}=\sigma_{H}$ (see Table 3) and $\sigma_{H}=29.4 \mathrm{kPa} / \mathrm{m}$ (Table 2), which corresponds to $\tau_{1}$ increasing with depth with a gradient of $3.8 \mathrm{kPa} / \mathrm{m}$ (Equation (A3), Appendix B). This $\tau_{1}$ gradient gives the value of $\tau_{1}$ at each depth needed to normalize the net pressure to obtain $F$ values according to Equation (2).

The $F$ values at lower-bound shear failure are larger in magnitude at shallow depths and decreases with depth (Figure 8a). In addition, the Mohr-Coulomb and Drucker-Prager criteria yield the narrowest and the widest safe drilling windows. On the other hand, the $F$ value at tensile failure (black solid) remains constant for the entire depth. This is because the $F$ values at tensile failure with the zero tensile strength solely depends on the in-situ stress and pore pressure (see Equations (1)). And since its gradients are assumed as constant for the entire depth, so are the $F$ values.

The magnitudes and trajectories of the maximum and minimum principal stresses in the plane of observation normal to the wellbore, at the moment of failure for each criterion, are depicted in Figure 9. At the center of the figure, the critical $F_{3}$ values at shear and tensile failure are graphed. Examples of the stress magnitude and trajectory plots are given for key depths for both the lower-bound of the safe drilling window (left panel) and upper-bound (right panel). In all images, the horizontal axes remain aligned with the maximum far-field in-situ stress direction $\left(\tau_{1}\right)$. The critical stress states at the lower-bound shear failure envelope are plotted on the left-hand side. The upper-bound shear and tensile failure envelopes occur on the right-hand side. At the top of the stress magnitude contour plots a scale is given for the normalized magnitudes of $\tau_{1}$ and $\tau_{2}$. The normalized magnitudes of the local deviatoric stresses near the wellbore appear smaller as the wellbore gets deeper (Figures 9-11), because the local deviatoric stresses increase slower with depth than the far-field deviatoric stress $(3.8 \mathrm{kPa} / \mathrm{m})$. The slow increase with depth of the local deviatoric stress occurs due to the $\chi$-value $\left(\chi_{3}=0.2\right)$ being small and fixed, while $F$-values are large at shallow depths (and decrease with increasing depth), as follows from Equation A16a-c. 


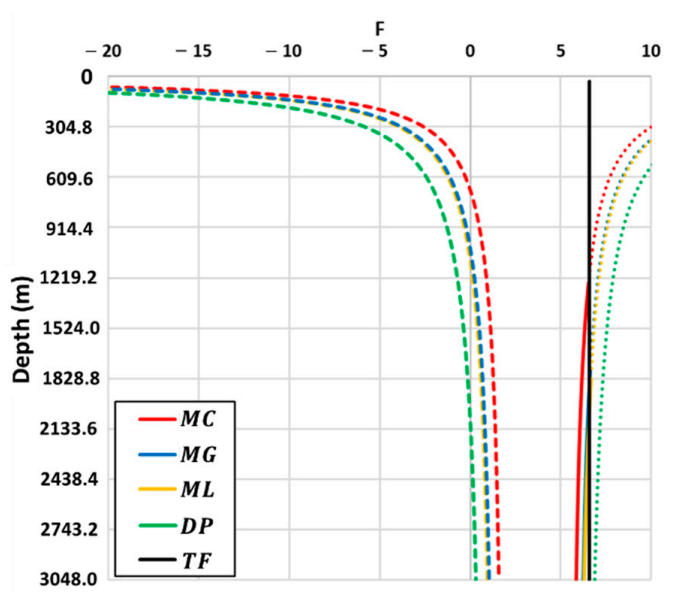

(a)

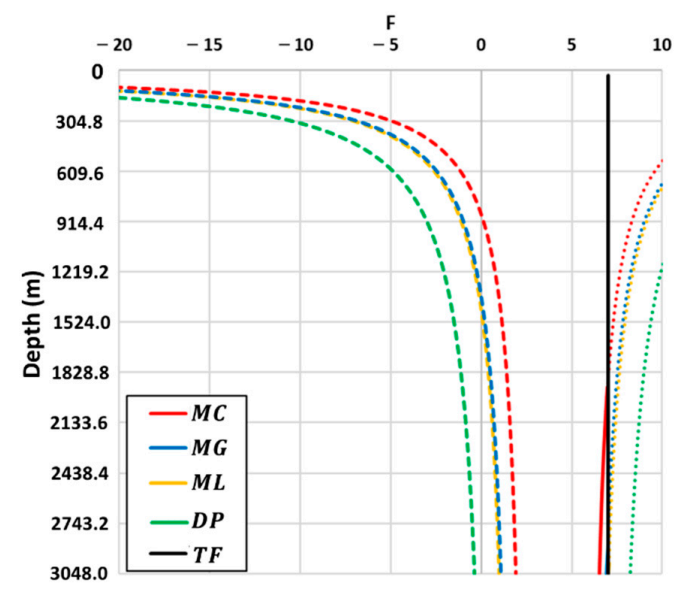

(b)

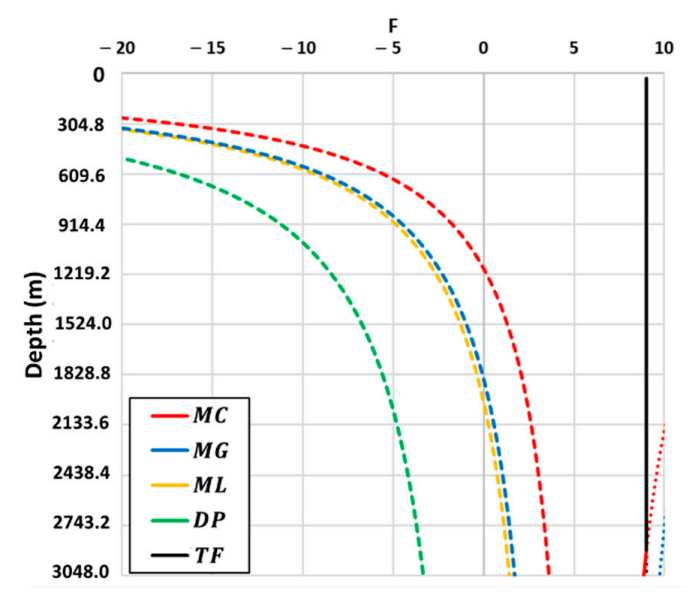

(c)

Figure 8. Frac number $(F)$ versus depth at failure. $F$ values at lower-bound (colored dashed) and upper-bound shear failure (colored solid) calculated by the Mohr-Coulomb (MC; red), Mogi-Coulomb (MG; blue), modified Lade (ML; yellow), and Drucker-Prager (DP; green) criteria, for the following cases: (a) Reverse faulting $\left(\chi_{3}=0.2\right)$, (b) strike-slip $\left(\chi_{2}=1\right)$, and (c) normal faulting $\left(\chi_{1}=5\right)$. F values at tensile failure (TF; assuming zero tensile strength) are depicted with the black solid line. 


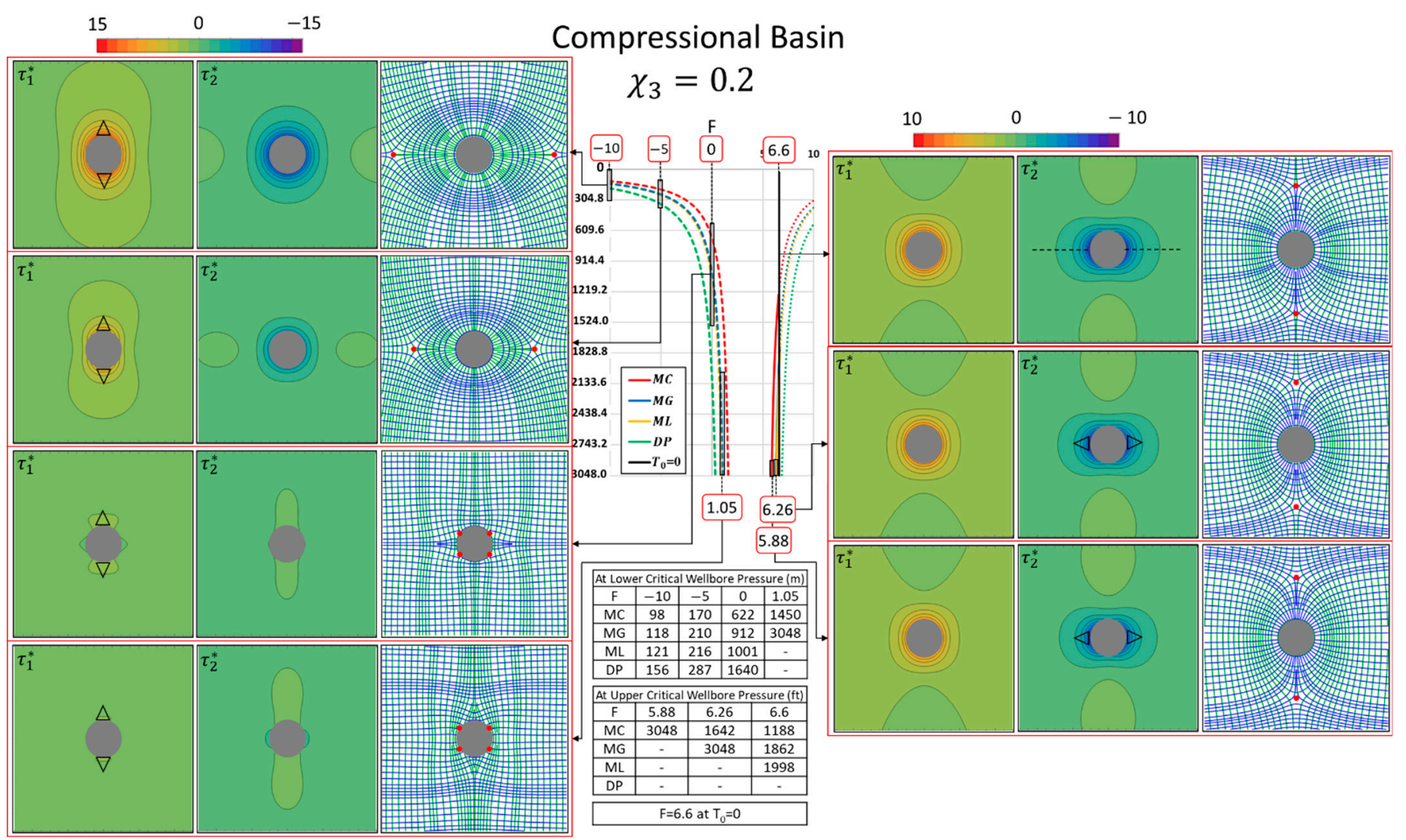

Figure 9. Dimensionless deviatoric stress magnitudes and trajectories for the compressional basin (reverse faulting) case at upper-bound (left-hand side) and lower-bound shear failure (right-hand side). For the zero tensile strength, tensile failure will occur at $F=6.6$. The color indices above the magnitude plots indicate the local stress intensity is normalized by the larger (compressional) far-field stress (see Appendix B.6). The triangles and dashed lines on the magnitude plots of the maximum principal stress at shear failure and of the minimum principal stress at tensile failure show the expected locations of failure. The blue and green curves, and the red dots in the stress trajectory plots represent the maximum and minimum principal stress trajectories, and the neutral points, respectively. The tables beneath the $F$ curves show the depths for each $F$ value calculated by the Mohr-Coulomb (MC), Mogi-Coulomb (MG), modified Lade (ML), and Drucker-Prager (DP) failure criteria. 


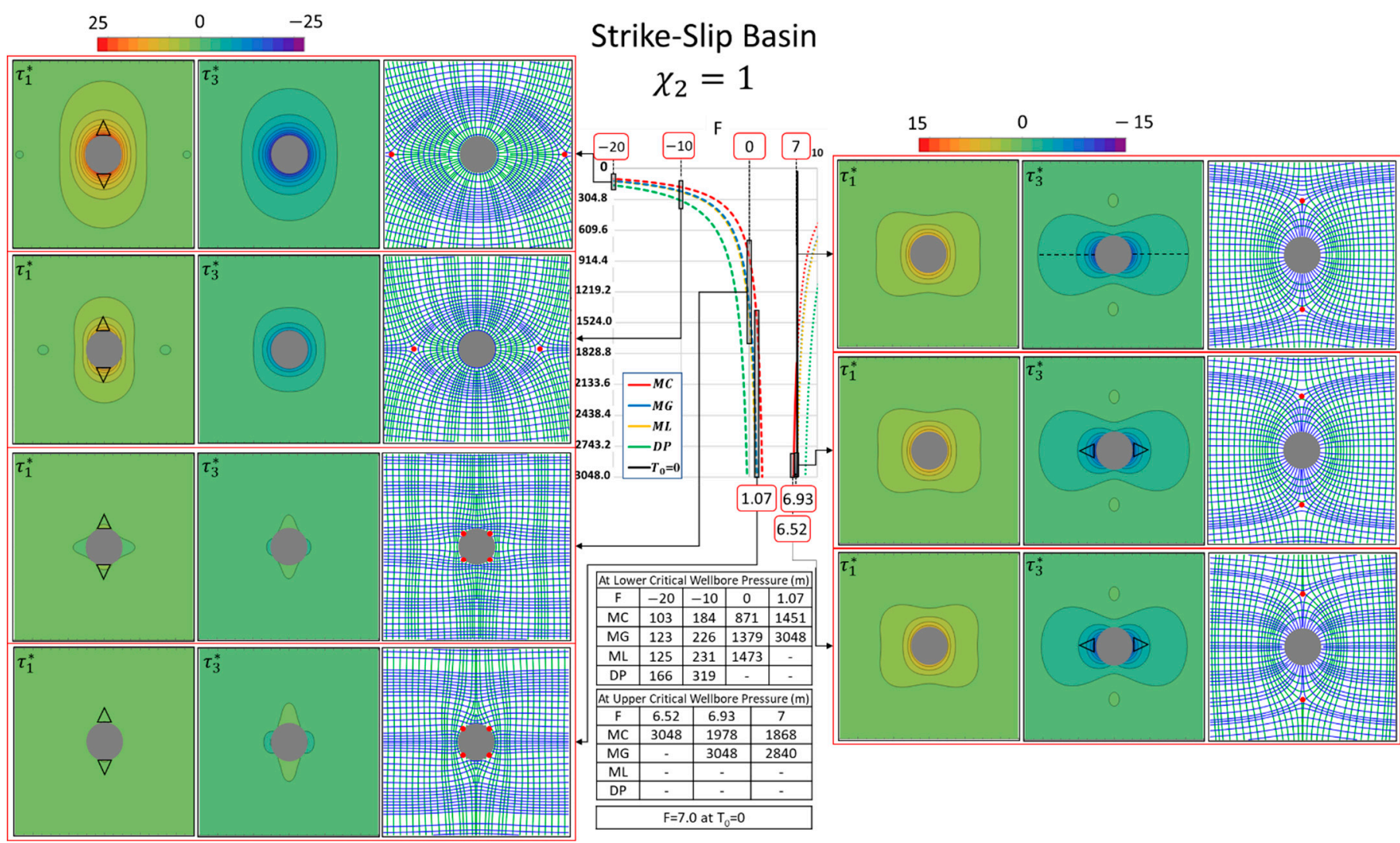

Figure 10. Dimensionless deviatoric stress magnitudes and trajectories for the strike-slip basin case at upper-bound (left-hand side) and lower-bound shear failure (right-hand side). For the zero tensile strength, tensile failure will occur at $F=7.0$. The color indices above the magnitude plots indicate the local stress intensity is normalized by the larger (compressional) far-field stress (see Appendix B.4). The triangles and dashed lines on the magnitude plots of the maximum principal stress at shear failure and of the minimum principal stress at tensile failure show the expected locations of failure. The blue and green curves, and the red dots in the stress trajectory plots represent the maximum and minimum principal stress trajectories, and the neutral points, respectively. The tables beneath the $F$ curves show the depths for each $F$ value calculated by the Mohr-Coulomb (MC), Mogi-Coulomb (MG), modified Lade (ML), and Drucker-Prager (DP) failure criteria. 


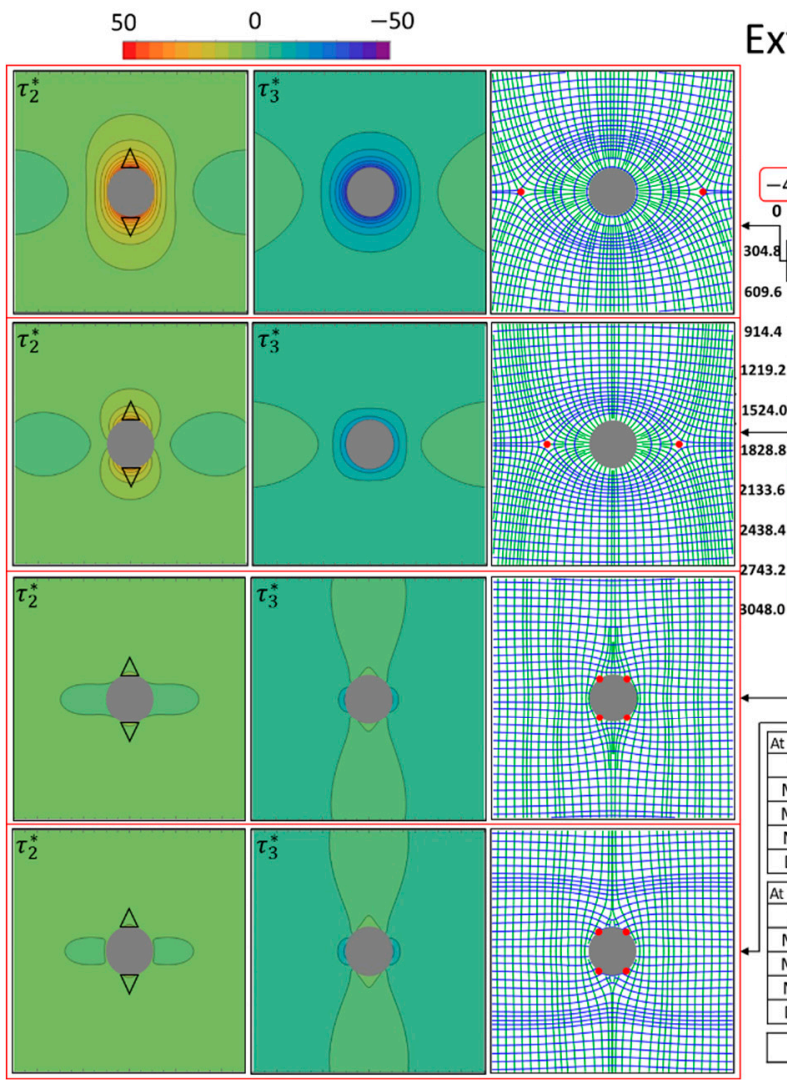

\section{Extensional Basin}

$$
\chi_{1}=5
$$

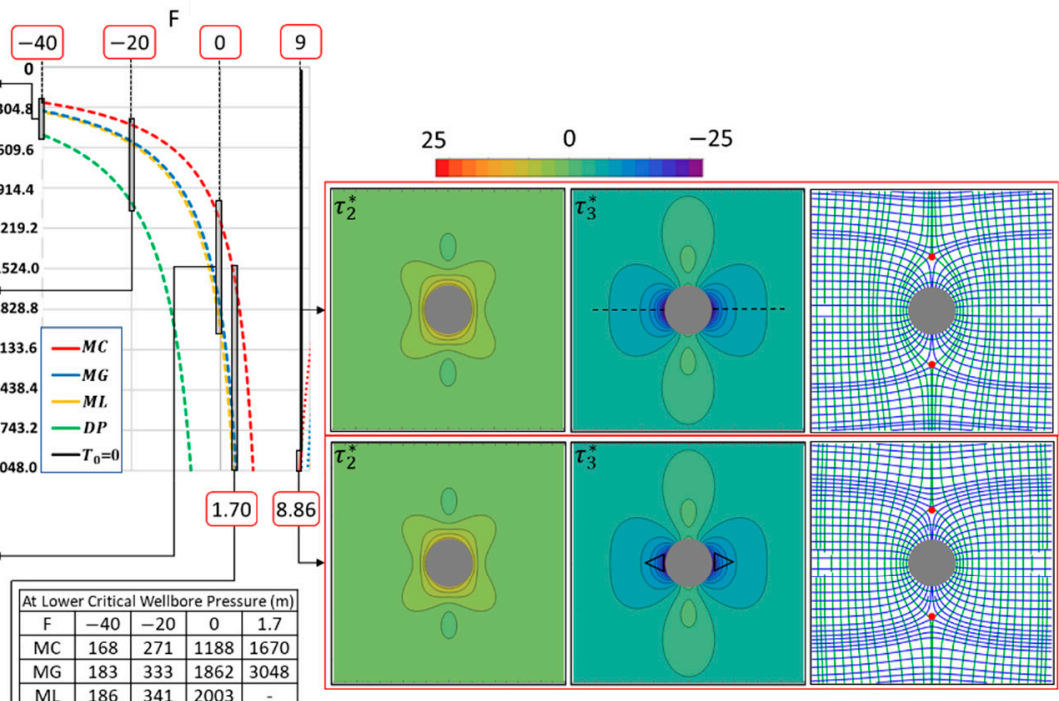

Figure 11. Dimensionless deviatoric stress magnitudes and trajectories for the extensional basin (normal faulting) case at upper-bound (left-hand side) and lower-bound shear failure (right-hand side). For the zero tensile strength, tensile failure will occur at $F=9.0$. The color indices above the magnitude plots indicate the local stress intensity is normalized by the intermediate (compressional) far-field stress (see Appendix B.5). The triangles and dashed lines on the magnitude plots of the maximum principal stress at shear failure and of the minimum principal stress at tensile failure show the expected locations of failure. The blue and green curves, and the red dots in the stress trajectory plots represent the maximum and minimum principal stress trajectories, and the neutral points, respectively. The tables beneath the $F$ curves show the depths for each $F$ value calculated by the Mohr-Coulomb (MC), Mogi-Coulomb (MG), modified Lade (ML), and Drucker-Prager (DP) failure criteria. 
The pairs of triangles on the maximum dimensionless principal stress plots and the dashed black lines on the minimum dimensionless principal stress plots indicate the locations of potential failure (triangles for shear failure and dashed lines for tensile failure). In the trajectory plots, the blue and green curves indicate the maximum and minimum principal stresses, respectively. The vertical and horizontal dimensions of the plots (in both the stress magnitude and trajectory plots) range from -5 to +5 times the wellbore radius. The magnitudes and trajectories are calculated for conditions at the failure envelope. Examples shown are for $F$ values of $-10,-5,0,1.05,5.88,6.26$, and 6.6, and are connected with the black-boxed intervals by black arrows. Beneath the $F$ chart, the depths are calculated for each of the four failure criteria to obtain the selected $F$ values.

At the third column of both sides of Figure 9, the maximum and minimum principal stress trajectories around the wellbore are depicted with blue and green curves, respectively. The red dots on the stress trajectory plots indicate the neutral points, where the principal stresses reverse their relationships with the radial and tangential stresses. For underbalanced wells $(F<0)$, the ellipse contoured by the trajectories within the neutral points indicates the fracture cage. The concept of the fracture cage was introduced by [2], who indicated that any radial fractures induced/present at the wellbore will, when propagating further, stay trapped inside the cage space. This is because the radial stress at the wellbore is negative and minimum, and the tangential stress is the maximum compressive stress within the fracture cage. Instead, concentric spalling may lead to wellbore widening. The fracture cage is not observed at the depths where $F \geq 0$, which means that fracture propagation radially away from the wellbore with risk of lost circulation is more likely to occur at the deeper portion of the vertical wellbore.

At the upper limit of the safe drilling mud weight window, the ellipse contoured by the stress trajectory (between the neutral points) has its long axis oriented vertically in the plot and thus is normal to the maximum horizontal stress, unlike the fracture cage at the lower-bound, which always has its long axis parallel to the maximum horizontal stress. For the upper-bound case $(F>0)$, the stress trajectory ellipse through the neutral points around the wellbore is termed a stress cage, inside which the induced stress concentration is higher than the minimum horizontal stress, and all tangential stress is tensional, as opposed to the fracture cage, where all tangential stress is compressional [27]. See Section 5.3, for more detailed explanation about fracture and stress cages.

The stress trajectories visualized in this section do not imply that failure will occur everywhere along the stress trajectories, because failure can only be determined by incorporating a failure criterion. The stress trajectories in fact show the static stress right before failure occurs and since failure is a dynamic process, the growth of either shear or tensile failure will progressively modify the stress distribution. However, the proposed stress trajectory visualization method provides important information about the potential failure paths. Additional discussion is given in Section 5.3.

\subsection{Strike-Slip Basin Case}

For the strike-slip case, the $\chi$-value $\left(\chi_{2}=1\right)$ is computed by converting $\left(\sigma_{H}, \sigma_{V}, \sigma_{h}\right)$ to $\left(\sigma_{1}, \sigma_{2}, \sigma_{3}\right)$ using Table 3 with values from Table 2. For this case, the maximum principal deviatoric stress normal to the wellbore $\left(\tau_{2}\right)$ increases with depth with a gradient of $2.3 \mathrm{kPa} / \mathrm{m}$, which can be calculated by Equation (A17).

The critical $F_{2}$ values at shear and tensile failure for the strike-slip case is shown in Figure 8b. Similar to the reverse faulting case (Figure 8a), the safe drilling window is wider for the shallow formations and narrows with depth. Although the strike-slip basin case has narrower width of the safe window in terms of the pressure shows than the compressional basin case (Figures 2 and 4 ), the range of $F$ values indicates an opposite trend (compare Figure $8 \mathrm{a}, \mathrm{b}$ ). This occurs because the gradient of the maximum deviatoric principal stress for the strike-slip case $(2.3 \mathrm{kPa} / \mathrm{m})$ is lower than for the reverse faulting case $(3.8 \mathrm{kPa} / \mathrm{m})$. Therefore, the critical $F$ values at lower-bound shear failure for the strike-slip case at the depth of $152 \mathrm{~m}$ are larger in magnitude and range from -21.78 to -12.64 , while tensile failure is expected to occur at $F=7.0$. 
In Figure 10, the dimensionless magnitudes, trajectories of the principal stresses and the depths for selected $F$ values are depicted. The range of values along the stress contour scale is larger for the strike-slip case ( \pm 25 for the lower-bound shear failure and \pm 15 for the upper-bound shear or tensile failure; Figure 10) than for the reverse faulting case ( \pm 15 for the lower-bound shear failure and \pm 10 for the upper-bound shear or tensile failure; Figure 9). This is because the maximum deviatoric principal stress gradient used to normalize the stress magnitudes for the strike-slip case $(2.3 \mathrm{kPa} / \mathrm{m})$ is lower than for the reverse faulting case $(3.8 \mathrm{kPa} / \mathrm{m})$. However, the $(\chi, F)$ pairs for both Figures 9 and 10 are correct and universal as $(\chi, F)$ plots have no "memory" for the normalization process itself. In other words, the normalization ensures unique solutions for the stress magnitude and stress trajectories are obtained. The principal stress trajectories indicate the likely occurrence of the fracture cage and stress cage at shallow depths for the lower and upper limit of the safe drilling window, respectively. However, the fracture caging effect is not observed below depths of 871, 1379, and $1473 \mathrm{~m}$ according to the Mohr-Coulomb, Mogi-Coulomb and modified Lade criteria. In addition, the strike-slip basin results show that the fracture caging effect disappears not until greater depths (Figure 10), which implies that the circumferential spalling fractures are more likely to occur and deeper than for the reverse faulting case (Figure 9).

\subsection{Extensional Basin Case}

The $\chi$-value $\left(\chi_{1}=5\right)$ for the extensional basin case can be similarly computed as for the other Andersonian cases by converting the $\left(\sigma_{H}, \sigma_{h}, \sigma_{V}\right)$ values from Table 2 to $\left(\sigma_{1}, \sigma_{2}, \sigma_{3}\right)$ values (Table 3$)$. Since the maximum in-situ horizontal stress is the intermediate principal stress $\left(\sigma_{2}=\sigma_{H}\right)$, the gradient of the maximum principal deviatoric stress normal to the wellbore $\left(\tau_{2}\right)$ is $0.7 \mathrm{kPa} / \mathrm{m}$ (Equation (A3), Appendix B).

Figure $8 \mathrm{c}$ shows the $F_{1}$ values at shear failure and tensile failure for the normal faulting case. The $F$ values have a larger range in magnitude at shallow depth, which decreases downward with depth. Due to the low gradient of the intermediate deviatoric stress $(0.7 \mathrm{kPa} / \mathrm{m})$, the $F$ values occupy a broad range at the margins of the safe drilling window for the normal faulting case (Figure 11). In contrast, the window of the critical wellbore pressure in the traditional presentation (Figure 6) is the narrowest of all the Andersonian cases. However, we emphasize that the traditional method of representing the safe drilling window graphs the wellbore pressure at failure (Section 3), whereas our complementary method graphs the $F$ scalar, which is the normalized net pressure on the wellbore. The combination of $(\chi, F)$ values then shows the unique stress trajectory patterns and stress magnitude contour plots in the plane of study normal to the wellbore, which we suggest provides valuable additional insight on wellbore stability and the failure paths in case the safe drilling window is overstepped. In accordance with the wellbore pressure values at failure (Figure 6), the Mohr-Coulomb criterion yields the most conservative results (Figure 11). Meanwhile, the values from the Drucker-Prager criterion show the widest safe window and a larger range of $F$ values.

Examples of the stress magnitudes and stress trajectories calculated for the selected $F$ values of $-40,-20,0,1.7,8.86$, and 9.0 for the normal faulting case are shown in Figure 11. Similar to the other Andersonian cases (Figures 9 and 10), the fracture and stress caging effects are significant at shallow depth and decrease as the wellbore advances deeper. According to the Mohr-Coulomb, Mogi-Coulomb and modified Lade criteria, the fracture caging effect disappears for wells deeper than 1188, 1862, and $2003 \mathrm{~m}$. Compared to the other Andersonian cases (Figures 9 and 10), the depths where fracture caging disappears for the normal faulting case (Figure 11) are the deepest. Therefore, the potential instability caused by circumferential fracture propagation is expected to persist deeper in such wells. In other words, the normal faulting case is the most prone to the fracture caging effect that induces the potential instability with circumferential fracture propagation. At the upper-bound, we observe that the stress caging effect persists up to $3048 \mathrm{~m}$ depth 


\section{Discussion}

A systematic analysis of the stress distributions around the wellbore at failure has practical value in wellbore stability analysis. In this discussion section, we highlight several key aspects observed from our analysis. Section 5.1 evaluates the impact of the rock strengths (such as cohesion and angle of internal friction) on the WBS model. Section 5.2 emphasizes the effect of the locally induced principal stresses at the failure locations on the WBS results. Implications of the stress trajectories are further discussed with the stress and fracture caging effects in Section 5.3. Section 5.4 briefly elaborates on the terms 'over-' and 'underbalanced wellbore' used in this study. Sections 5.5 and 5.6 analyze the induced tensile failure and the effect of depth on the occurrence of fracture cages, respectively. Directions for future work are given in Section 5.7.

\subsection{Sensitivity Analysis: Effect of Rock Strength Variations}

In Sections 3 and 4, a systematic wellbore stability analysis was performed using input parameters selected from the gathered field data (Sections 2.1 and 2.2). Since the present study covers a wide range of depths, the initial analysis assumed constant strengths at each depth. In any particular drilling location, the rock strengths may vary with depth, lithology, discontinuities, etc. Here we expand our analysis with critical wellbore pressures by considering a certain variation in the rock strength, related to such factors as the cohesion and internal friction angle. For the cohesion, a higher value of 13.8 MPa was selected (instead of 6.9 MPa used in the main analysis, Section 2.1) as there are field cases with the cohesion value of 12.4 and 19.8 MPa (Table 1). In addition, the internal friction angle can be very low for shale formation (as low as $15^{\circ}$ ), where many wellbore instability problems occur [28]. Therefore, the internal friction angle of $15^{\circ}$ (instead of $40^{\circ}$ used in the main analysis, Section 2.1) was evaluated for a comparison of the critical wellbore pressure. In this section, only the Mogi-Coulomb failure criterion was evaluated, as it yields critical values that are intermediate in the range between the conservative Mohr-Coulomb and the more liberal Drucker-Prager criteria.

Figure 12a shows the upper and lower critical wellbore pressures, calculated by the Mogi-Coulomb failure criterion. Different line colors distinguish the three Andersonian cases, i.e., reverse faulting (RF; compressional basin; red), strike-slip (SS; green) and normal faulting (NF; extensional basin; blue). The solid lines represent the results for the base case (the cohesion of 6.9 MPa and the internal friction angle of $\left.40^{\circ}\right)$, while the dashed lines show the effect of the higher cohesion case $(13.8 \mathrm{MPa})$. The lower-bound shear failure is expected to occur at lower wellbore pressure for all the Andersonian cases if a wellbore is drilled in a formation with the higher cohesion of $13.8 \mathrm{MPa}$ (Figure 12a). In the same manner, the upper critical wellbore pressure will be higher than for the base case when the formation has the decreased internal friction angle of $15^{\circ}$ (Figure $12 b$ ). The critical wellbore pressures at tensile failure for both the base and modified cases are identical, due to the zero tensile strength assumption.

Arrows at the base of the plots (Figure 12a,b) indicate the width of the safe drilling window for each of the Andersonian cases. The results indicate that, for all three Andersonian cases evaluated here, when a wellbore penetrates a formation with a higher cohesion, the safe windows will be wider than for the lower cohesion formations. On the other hand, when a wellbore encounters a formation with a lower cohesion, the safe window will further narrow than for the 6.9 MPa cohesion used in the base case. Separately, if a well encounters a formation with the lower internal friction angle $\left(\phi=15^{\circ}\right)$ the safe drilling window will be significantly narrower than for the base case $\left(\phi=40^{\circ}\right)$ (Figure 12b). This conclusion applies to all three Andersonian cases evaluated. In such weaker formations, the lower and upper critical wellbore pressures attain a very narrow range for safe drilling. In fact, we can conclude from Figure $12 b$ that, under the normal faulting regime, a safe margin for the drilling fluid weight does not exist if the wellbore trajectory crosses a formation with such a low friction angle $\left(15^{\circ}\right)$. As the dashed blue curves show in Figure 12b, the two failure gradients converge and cross over at a certain depth, indicating that shear failure will always be induced beyond that drilling depth, regardless of the wellbore pressure. As stated above, the low internal friction angles (as low as $15^{\circ}$ ) are particular for 
shale formation, which according to our analysis may be a root cause of wellbore instability problems in shales.

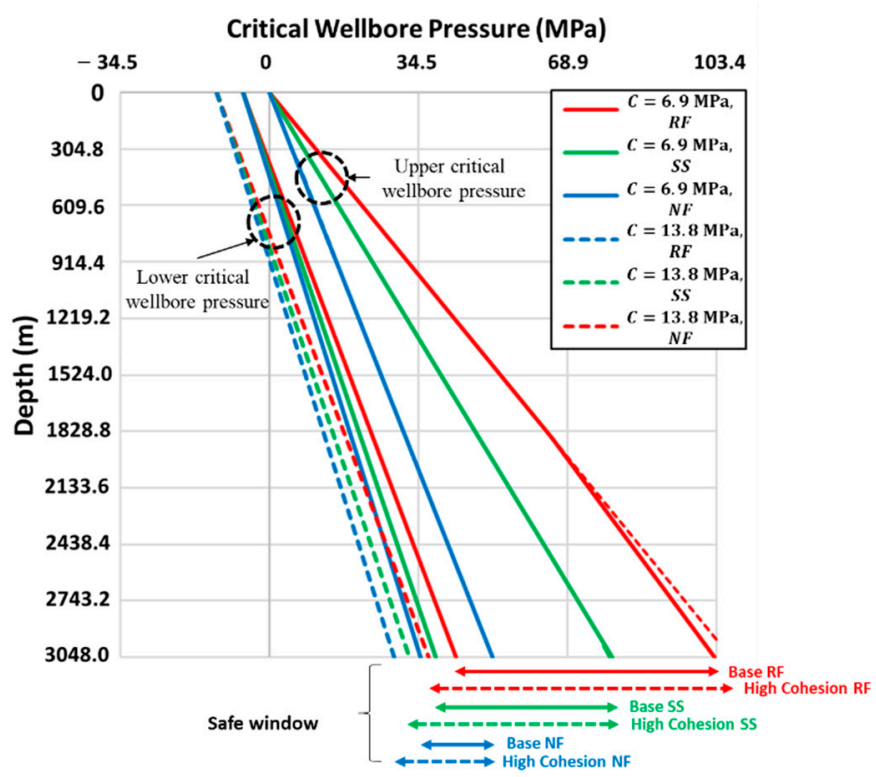

(a)

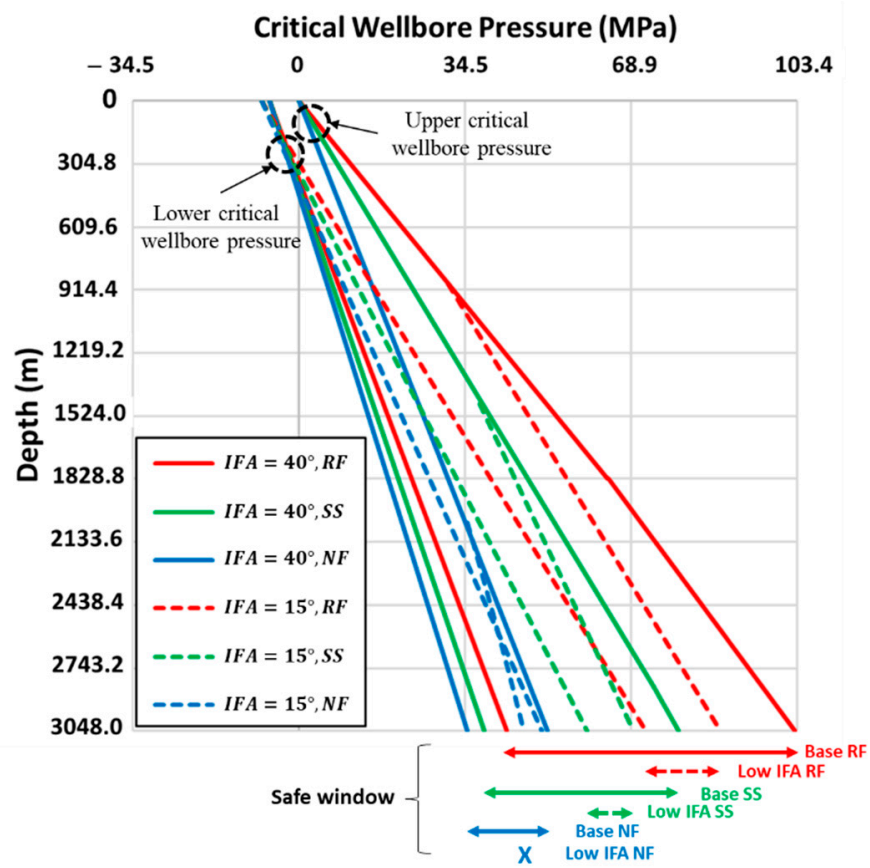

(b)

Figure 12. Comparison of the critical wellbore pressure calculated by the Mogi-Coulomb failure criterion. The dashed lines show the critical wellbore pressure with (a) the cohesion of $13.8 \mathrm{MPa}$ and (b) the internal friction angle of $15^{\circ}$. The solid lines indicate the base case (the cohesion of $6.9 \mathrm{MPa}$ and the internal friction angle of $40^{\circ}$ ). The colors represent the Andersonian cases, i.e., reverse faulting (RF; compressional basin; red), strike-slip (SS; green) and normal faulting (NF; extensional basin; blue). The arrows below the plots indicate the safe windows at $3048 \mathrm{~m}$.

As many shale drilling operations occur in normal faulting basins, additional analysis was performed to determine the critical wellbore pressure comparing the effect of various shear failure criteria: i.e., the Mohr-Coulomb, Mogi-Coulomb and modified-Lade failure criteria (Figure 13). For all shear failure criteria, wellbore instability problems become unavoidable when the low internal friction 
angle $\left(15^{\circ}\right)$ is adopted, and will occur at 2046, 2581, and $2702 \mathrm{~m}$, respectively (failure depths are marked by red, blue and green dots in the magnified section, Figure 13). For the Drucker-Prager (DP) failure criterion, the most liberal failure criterion, (green lines in Figure 13), the drilling window converges slower and becomes unsafe beyond $3048 \mathrm{~m}$ depth. Our findings suggest that for the safe drilling window determination in shale formations, laboratory measurements of the internal friction angle using core samples is extremely important. Such measurements can reduce the considerable uncertainty in the determination of the safe drilling window. The importance of reduction in uncertainty was previously highlighted by McLean and Addis [29] who stated that the WBS effects overlooked due to analysis in the plane normal to the wellbore (and implied neglect of the third principal stress axis parallel to the wellbore) is relatively small as compared to the inaccuracies related to (and lack of) measurements of the variability in rock strengths and in-situ stresses.

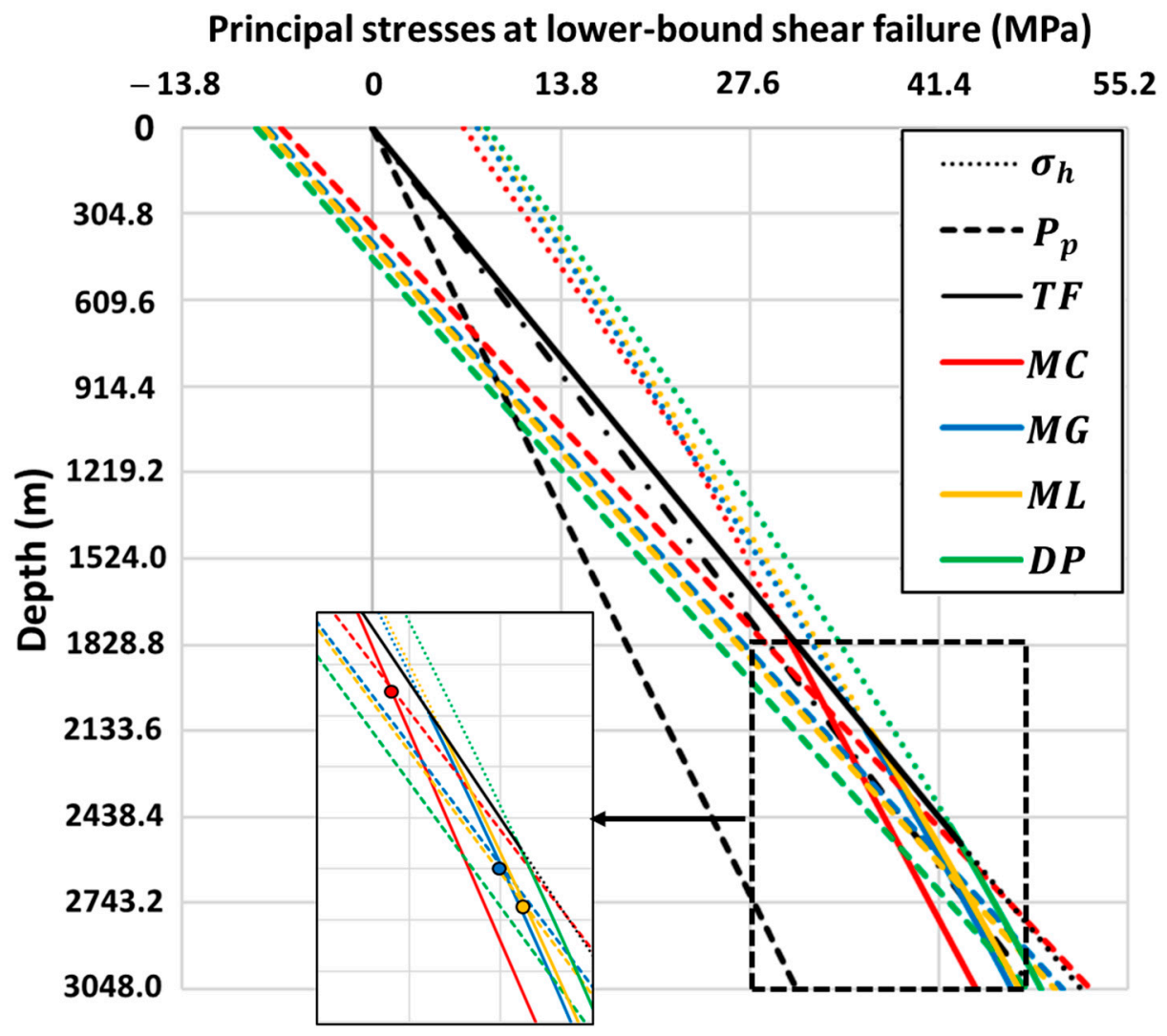

Figure 13. Critical wellbore pressure at lower- (colored dashed), upper-bound shear (colored solid) and tensile (TF; black solid) failures under the normal faulting case with the vertical, maximum, and minimum horizontal stress gradients of $22.6,20.4$, and $15.8 \mathrm{kPa} / \mathrm{m}$, respectively. The internal friction angle is $15^{\circ}$. The pore pressure gradient is $10.2 \mathrm{kPa} / \mathrm{m}$ (black dashed). The wellbore pressures were calculated by the Mohr-Coulomb (MC; red), Mogi-Coulomb (MG; blue), modified Lade (ML; yellow), and Drucker-Prager (DP; green) failure criteria. The minimum horizontal in-situ stress is depicted with the dash-dotted black line. The magnified frame indicates that the lower and upper critical wellbore pressures cross at certain depths, according to the MC (red circle), MG (blue circle), and ML criteria (yellow circle). 


\subsection{Effect of Principal Stresses at Failure Location}

During the wellbore stability analysis, calculating the critical wellbore pressures that induces shear or tensile failure, and results in potential instability is one of the crucial steps. Since each failure criterion yields different outcomes, how to select the reliable failure criterion has been a question drawing researchers' interest. Although there have been many studies focusing on the topic, a comprehensive analysis in a wellbore stability setting to explain differences in the results has not been attempted before. For example, prior studies have noted that the Mohr-Coulomb criterion, by not taking into account the effect of the intermediate stress, underestimates the rock strength [12-15]. In order to closely investigate the differences yielded by the criteria, however, it is necessary to include in the analysis the principal stresses at the failure location as influenced by the presence of the wellbore. The local stress deviations are limited to a region within 10 times wellbore radius away from the wellbore [30]. However, such localized stress redistributions and stress concentrations near the wellbore are very important in the wellbore stability analysis, because prediction of the instability is determined by the deviated stress conditions at the potential failure locations. Based on our analysis on the local principal stresses, we conclude that the locally induced axial principal stress is always intermediate for all the cases, except for the upper-bound shear failure for the normal faulting case. For this case, the radial principal stress is the maximum principal stress at shallow depth and becomes the intermediate one. This phenomenon is exclusively observed in the normal faulting case because the vertical in-situ stress gradient, which affects the axial stress, is maximum. As a result, the calculated critical wellbore pressure shows unique behaviors where reversal of the principal stress occurs, such as the sudden change of the gradient (Figure $6 \mathrm{~b}$ ). Therefore, the principal stress condition at the failure location needs to be taken into account for the critical wellbore pressure analysis.

In practice, not only does the order of the local principal stresses affect the rock strength, but it may also have an influence on the failure behavior. When the axial stress is the maximum and the tangential stress is the minimum, the failure plane will have a high angle and tend to align with the axial/tangential direction (see Table 3 in Pašić, et al. [31]). When the radial stress is the maximum and the tangential stress is the minimum (at the interval less than $1147 \mathrm{~m}$ for the extensional basin case), the rock has nowhere to go because there is no room for detached shear movement 'into' the wellbore. However, this kinematic aspect is different from the dynamic aspect: Elastic deformations are small and the rock will still fail when the stress reaches the shear failure criterion. However, when the kinematics prevents the fragment from shearing 'into' the wellbore, then what happens is that the fragment tends to stay in place, unless ripped out by the flow of drilling fluid up the annulus.

\subsection{Importance of Stress Trajectories, Stress Cages, and Fracture Cages}

When the stress condition around the wellbore is analyzed, the stress concentrations are traditionally the only parameters of interest in the standard wellbore stability analysis tools. However, the trajectories of the principal stresses also provide valuable information about the potential instability and the induced fracture propagation direction as we highlighted in Section 4 of this study. Our study computes and visualizes the stress trajectories around the wellbore at the moment of failure. We would like to emphasize that the stress trajectory lines themselves are not valid rock failure criteria, because they do not prove failure in compression nor failure in tension. To predict the likely failure locations, the stress magnitudes must be compared to failure criteria, in order to determine if fractures will be created. We therefore apply the relevant shear criterion for shear fractures (and possible axial splitting in the case of extremely low effective minimum stress), and a tensile criterion (zero tensile strength) is used for tensile fractures. Prior work [31,32] has indicated that the induced tensile failure direction will align with the direction of the maximum principal stress for a given differential stress condition. Shear failure occurs along slip lines at $45^{\circ}$ to the principal stress trajectories or at a lower angle according to the internal friction angle friction for a specific rock formation [1].

In addition to the stress trajectories, determination of the detailed locations of the neutral (or isotropic) stress points provides useful information about the fracture and stress caging effects. The 
terms 'fracture cage' and 'stress cage' are used in our study to distinguish the following stress states around the wellbore, when the neutral points are no longer occurring at the wellbore rim (as is the case for a Frac number equal to zero), but at some distance. The two states can be distinguished $[1,33]$ as follows:

(1) When the radial deviatoric stress in an elliptical region near the wellbore is compressive (positive convention used here) and thus maximum, and the tangential stress is the minimum tensile stress, this is called a stress cage. The term 'stress cage' has been used to describe the rise in tangential stresses around a wellbore due to dilation and propping of early radial fractures [27,34,35]. According to our approach a positive Frac number is a prerequisite for the occurrence of a stress cage.

(2) When the radial deviatoric stress in an elliptical region near the wellbore is tensile (negative) and thus minimum, and the tangential stress is the maximum compressive stress, this is called a fracture cage. The term was first introduced in Weijermars [30] as follows: "-Confined space around borehole where the principal deviatoric tension stress follows concentric rings so that any radial fracture emanating from the wellbore into the fracture cage space will remain trapped inside and rotate into the direction of the concentric tension rings. A negative Frac number is a prerequisite for the occurrence of a fracture cage."

The terms 'fracture cage' and 'stress cage' refer to the stress state near the wellbore, which in turn is due to the state of the actual pressure balance at each depth (related to borehole stability). Fracture cages occur in wellbores with underbalanced pressure. Stress cages occur when the wellbore pressure is overbalanced.

\subsection{Underbalanced and Overbalanced Wellbore Pressures}

Industry commonly relates the terms underbalanced and overbalanced to mud weight versus pore pressure, which are design terms when used in conjunction with "drilling" as in underbalanced drilling and overbalanced drilling. Generally, the casing program is designed to maintain a slight overbalance in the corresponding wellbore section (until protected by casing). In our study, the terms underbalanced and overbalanced wellbore are employed to describe the actual pressure balance at specific depths in the wellbore. For example, in practical drilling operations an overbalanced drilling program may still encounter, due to incomplete information, anomalously high formation pressures that can render a specific section of the wellbore underbalanced. Ultimately, the state of the actual pressure balance at each depth (related to borehole stability) depends upon: (1) The native stress and pore pressure state, (2) mechanical properties of the formation (here assumed isotropic elastic), and (3) the orientation of the wellbore (here assumed parallel to one of the principal stresses), with the safe mud pressure window defined by the failure criteria at each depth.

\subsection{Tensile Failure and Fracture Propagation}

At very shallow depths at the upper-bound of the safe drilling window (Figures 9-11), tensile failure may occur. As soon as tensile radial fractures form in the wellbore, part of the excess fluid pressure in the fracture space will be relieved. However, not all excess pressure may be instantaneously relieved when such radial fractures form. Considering that the whole wellbore is filled with drilling fluid, only a large amount of circulation loss would significantly decrease the wellbore pressure instantly. However, this does not need to be the case for every generated tensile fracture. In addition, when the targets are ultra-low permeability reservoirs (such as unconventional shale formations), the magnitude of the leak-off fluid and associated wellbore pressure reduction commonly remains limited. Therefore, one may suggest that induced tensile fractures may propagate some distance, especially in shales, and will closely follow the maximum principal stress trajectories (which are radial in stress cages) at initial failure, until the tangential stress becomes higher than the fluid pressure in the tensile fracture. 
Tensile failure is rarely considered at the lower-bound of the safe drilling window (Figures 9-11), but may be more common than actually recognized. Generally at shallower depths (less than 914 to $1524 \mathrm{~m}$ deep), the stress condition of a fracture cage occurs in wellbores, as highlighted by the stress trajectories at the lower-bound failure envelopes (Figures 9-11). Spalling (tangential tensile fractures) may occur when the wellbore pressure is lower than the formation pore pressure, and two distinct conditions need to be considered. In high permeability rocks any pore fluid leading to the excess formation pressure simply flows into the well immediately after the rock is penetrated by the drill bit. Consequently, spalling and sustained underbalanced wellbore pressure are less likely to occur in high permeability rocks and in the absence of clay smear on the wellbore. However, in low permeability rocks like shales, the occurrence of anomalously high formation pressures is common. The overpressure is confined in the nano-pores of such rocks and may not quickly escape to the wellbore and thus favors the occurrence of spalling.

As Weijermars, Zhang and Schultz-Ela [2] indicated, the fracture caging effect is very important to analyze in wellbore stability studies, especially when initial cracks occur in the formation. Natural fractures are abundant in nature, but when a wellbore with a relatively low mud weight penetrates an over-pressured formation, the stress condition of a fracture cage may preclude the radial propagation of any fractures initially at a high angle to the wellbore, because the compressional tangential stress of the fracture cage would close the radial fracture. Figure 14a,b show a numerical model of the situation with a negative radial deviatoric stress, due to the formation fluid pressure in an open wellbore being higher than the pressure due to the weight of the drilling fluid column (or when casing shields the wellbore rock from the pressure of the drilling fluid inside the casing [36]). The stress magnitudes indicated in Figure 14a,b are total stresses for an assumed plane stress condition meaning that the axial stress along the wellbore (normal to the image) is equal to the mean stress or confining pressure state in the rock (here equal to $(40+80) / 2=60 \mathrm{MPa}$ ). The radial stress on the wellbore is independently controlled by the net pressure due to the fluid pressure in the pore network of the rock on the exterior of the wellbore and the pressure due to the weight of the drilling fluid on the interior of the wellbore.

The directions of the numerical fracture propagation (Figure 14a,b) and independently modeled analytical stress trajectory contours are overlaid in Figure 14c, and match very closely. As shown in Figure 14c, the tip of the long crack initially placed out of the fracture cage propagates outward, and escapes the cage and will eventually align with the far-field maximum principal stress direction. However, the short crack cannot escape the fracture cage and its propagation turns around the wellbore following the maximum stress trajectory, essentially acting as a nucleus for spalling of rock inside the fracture cage. The fracture propagation in the numerical model of Figure 14a,b is only possible when the fluid injected in the fractures does not result in removal of the negative net pressure on the wellbore.

The source of fluid fill of a pre-existing radial fracture cannot be the wellbore fluid (and was indeed a separate injector [30] in the models of Figure 14a,b), because (1) compressional tangential stress of the fracture cage would tend to close and possibly seal the radial fracture, and (2) the pore pressure is higher than the wellbore pressure. This might suggest that the risk of failing a fracture cage is very low. Yet, we propose not to rule out the tensile failure of a fracture cage. The wellbore penetration lowers the minimum tensile stress near the wellbore, and in an over-pressured formation the source of the injection fluid may be from the rock matrix, with the tip of a radial fracture of suitable length acting as the initiation point of the tangential tensile failure. 


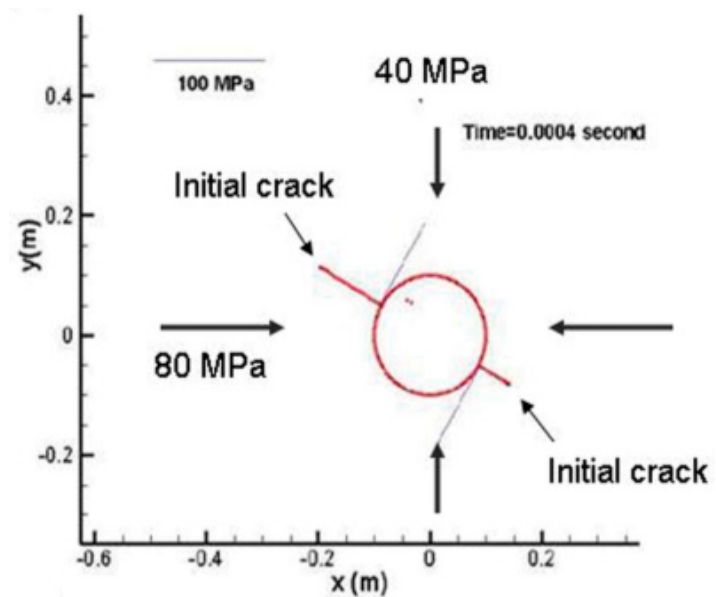

(a)

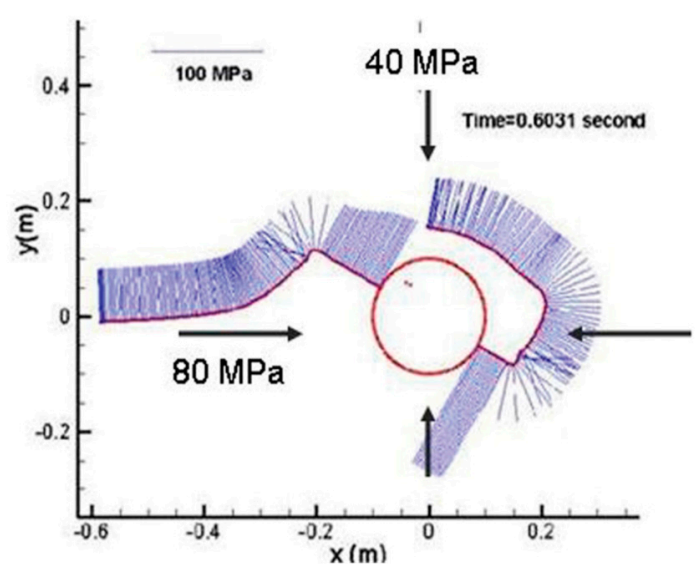

(b)

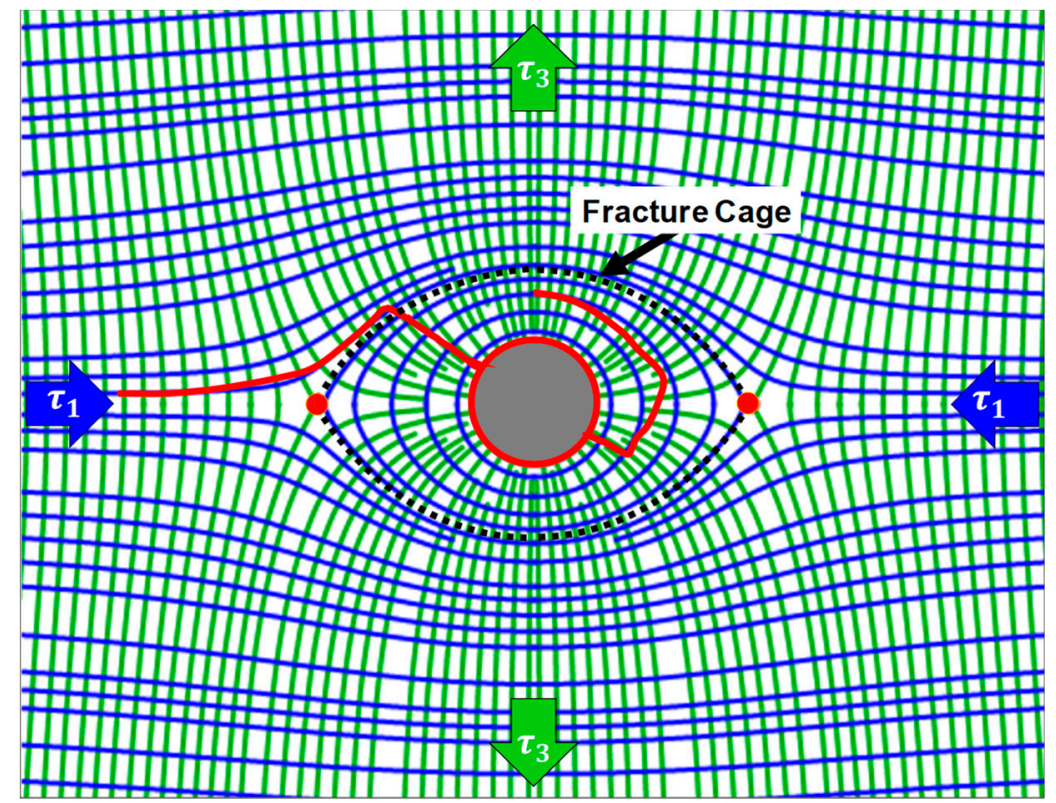

(c)

Figure 14. Comparison of the stress trajectories with the numerical simulation results when maximum and minimum total principal stresses normal to the wellbore are $80 \mathrm{MPa}$ and $40 \mathrm{MPa}$, respectively [2]. Two initial cracks are placed at the wellbore wall with the length of 0.64 (right fracture) and 1.28 times (left fracture) the wellbore radius. The dimensionless variables $\chi$ and $F$ are -0.5 and -1.66 , respectively. The results are (a) at time 0.0004 and (b) 0.6031 second. (c) The numerical fracture propagation result and the analytical stress trajectory contours are overlaid and match closely.

\subsection{Fracture Caging and Depth}

Another important insight from the present systematic study is that the risk of fracture caging effects tends to disappear as the well gets deeper. The fracture caging phenomenon is mostly observed in the shallower portions of the wellbore, i.e., at the depths where the $F$ values are negative. Practical observations of the shape of drill cuttings may help to identify the depth where the fracture caging effect ceases to occur. Assume a vertical wellbore is drilled in a formation as shown in Figure 15a. The blue and red lines indicate the lower and upper critical wellbore pressures, respectively. The yellow tubulars represent the casings of wellbore segments. At the bottom of each casing change, the occurrence of the fragments due to shear failure is likely to be observed in the shale shaker. When the critical wellbore pressure is converted to the $F$ domain (Figure 15b), the corresponding stress trajectories at failure for each depth can be obtained (Figure 15c,d, respectively). When the well depth 
is shallow and the fracture caging effect exists, the rock fragments will be gently curved as the cavings are bounded by the principal stress trajectories ( $\tau_{1}$ and $\tau_{3}$ in Figure $\left.15 b\right)$. For deeper wells, the fracture caging effect wanes and the caving fragments are more likely to appear as angular cavings with shapes controlled by the shear failure process (Figure 15c). In this case, the cavings are most likely to be bounded by the shear slip lines.

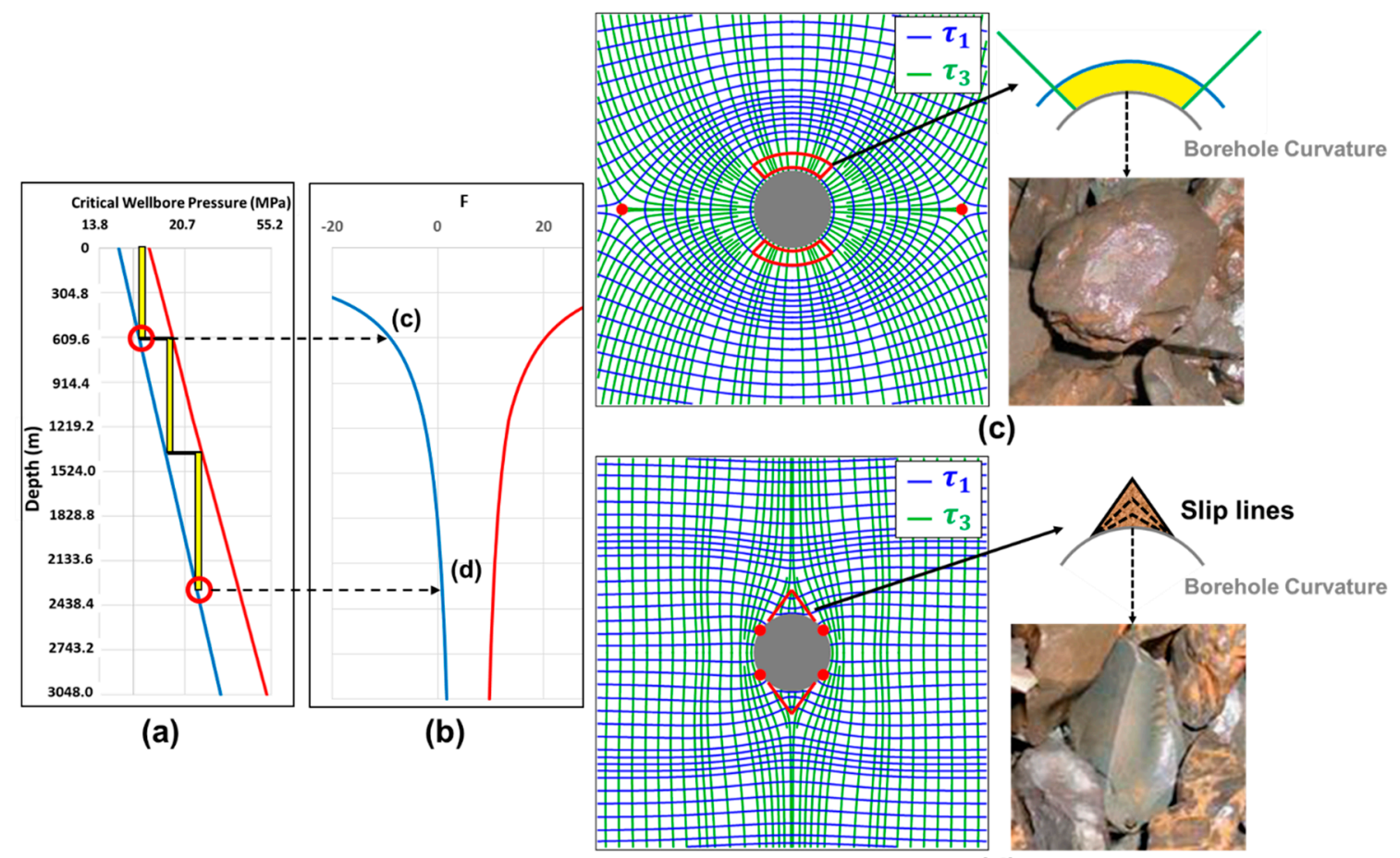

(d)

Figure 15. Casings of the wellbore segments placed between (a) the critical wellbore pressures and (b) the critical $F$ values. (c) Gently curved caving shapes (spalling) from shallow formation. Cavings bounded by principal stress trajectories. (d) Angular caving shapes (shear failure). Cavings bounded by slip lines between two principal stresses.

\subsection{Further Work}

Examples of WBS analyses for horizontal wellbores, using field data from US shale basins and accounting for elastic anisotropy (assuming transverse isotropy) have been given in recent companion studies [37-39]. Although the analyses performed in the present is study solely focus on a vertical wellbore under three Andersonian cases, and assuming linear and isotropic elasticity, the proposed procedures can be equally applied to a horizontal wellbore. Instead of using synthetic cases, the method can be applied to an actual wellbore using a 3D Mechanical Earth Model, in which case abnormal pore pressures and local variations of the in-situ stresses can all be accounted for by computing the Frac number and the Bi-axial Stress scalar. Further validation of our model using specific field data is planned in future work.

\section{Conclusions}

This study presents a new interface that provides practical information for WBS studies and uniquely includes the stress trajectories and deviatoric stress magnitudes at every depth in a vertical wellbore at the moment of failure. Three Andersonian cases were considered, using field data from literature. The Mohr-Coulomb, Mogi-Coulomb, modified Lade and Drucker-Prager failure criteria were used to determine the critical wellbore pressures at upper- and lower-bound shear failure. Tensile strength was also calculated to examine whether the stresses induced by the wellbore pressure would favor tensile failure or shear failure. Key aspects observed from this study are as follows, 
(1) At shallow depth, at the upper-bound of the safe drilling window, tensile failure is more likely to occur than shear failure. In the upper section of the well trajectory, tensile failure is triggered by lower wellbore pressures than shear failure. The traditional analysis of the safe drilling window shows that at the upper boundary, tensile failure prevails at shallower depths and shear failure prevails in deeper wells. the stress trajectories show the likely locations and propagation directions of the tensile failure and shear failure (the latter assuming transposition of stress trajectories with shear slip lines).

(2) The actual transition depth for either tensile of shear failure to prevail was evaluated for each of the three Andersonian cases and varies with the shear failure criterion used. All plausible cases have been evaluated in our study. The critical wellbore pressure gradients for both shear and tensile failure normally appear either linear or change gradually when the formation properties remain constant with depth. However, the shear failure gradient at the upper-bound of the safe window, in the extensional basin (normal faulting) case, showed a sudden change in the gradient occurs at a depth of $1147 \mathrm{~m}$. According to the integrated analysis with the local principal stress states at the failure location, the change in the critical wellbore pressure gradients is caused by a reversal of the principal stress order. In all cases, our analysis shows that the locally induced principal stress condition needs to be taken into account for a more reliable wellbore stability analysis.

(3) As previous studies pointed out [1], the pattern of deviatoric stress concentrations and stress trajectories near the wellbore solely depend on two dimensionless variables, the Frac number $(F)$ and the Bi-axial Stress scalar $(\chi)$. The range of plausible $F$ values was analyzed for three Andersonian cases (each with a fixed $\chi$ value). The $F$ chart is a new graphical interface that can provide valuable additional information for wellbore stability analysis, both prior to drilling and real-time during drilling operations to enhance monitoring of the well response. The examples presented in Figures 9-11 show that the range of $F$ values narrows with increasing depth at the boundaries of the safe drilling window. The $F$ value at tensile failure depends on gradients of the in-situ stress and pore pressure, which are assumed constant in this study.

(4) According to the magnitudes and trajectories of the maximum and minimum principal stresses, fracture caging effects are most significant for shallower wells and decreases with depth. In contrast, the stress cage effect at the upper-bound of the safe drilling window occurs at all depths in the well for each of the Andersonian cases considered here.

For a comparison analysis on rock strengths, additional cases for higher cohesion (13.8 $\mathrm{MPa})$ and lower internal friction angle $\left(15^{\circ}\right)$ were investigated. The results indicate that if a well penetrates a formation with the higher cohesion value, the margins of the safe drilling windows will be wider, for all three Andersonian cases. The results further indicate that under the normal faulting regime, wellbore instability is unavoidable for formations with a low internal friction angle: shear failure will always occur beyond a certain drilling depth, regardless of the wellbore pressure. Since many shale drilling operations occur in normal faulting basins, the low internal friction angles (as low as $15^{\circ}$ ), which may particularly apply to shale formations, may be a potential cause of the observed wellbore instability problems at those depths where a safe margin for the drilling fluid weight does not exist.

Supplementary Materials: Detailed algorithms for the various rock failure criteria used in this study are given in an online supplement to this article. The following are available online at http://www.mdpi.com/1996-1073/12/20/ 4019/s1.

Author Contributions: Conceptualization, J.W. and R.W.; Methodology, J.W. and R.W.; Formal Analysis, J.W. and R.W.; Writing-Original Draft Preparation, J.W.; Writing-Review and Editing, J.W. and R.W.; Funding Acquisition, R.W.

Acknowledgments: This study was funded by start-up funds from the Texas A\&M Engineering Experiment Station (TEES) to Ruud Weijermars.

Conflicts of Interest: The authors declare that they have no conflict of interest. 


\section{Nomenclature}

$F_{i} \quad$ Frac number when the wellbore is aligned with $\sigma_{i}$ (dimensionless)

$P \quad$ Mean stress (Pa)

$P_{N E T} \quad$ Net pressure, i.e., $P_{w}-P_{p}(\mathrm{~Pa})$

$P_{w} \quad$ Wellbore pressure $(\mathrm{Pa})$

$P_{p} \quad$ Pore pressure $(\mathrm{Pa})$

$\chi_{i} \quad$ Bi-axial stress scalar when the wellbore is aligned with $\sigma_{i}$ (dimensionless)

$\sigma_{V} \quad$ Vertical principal stress $(\mathrm{Pa})$

$\sigma_{H} \quad$ Maximum horizontal principal stress (Pa)

$\sigma_{h} \quad$ Minimum horizontal principal stress $(\mathrm{Pa})$

$\sigma_{1} \quad$ Maximum principal total stress (Pa)

$\sigma_{2} \quad$ Intermediate principal total stress $(\mathrm{Pa})$

$\sigma_{3} \quad$ Minimum principal total stress $(\mathrm{Pa})$

$\sigma_{z} \quad$ Total axial stress $(\mathrm{Pa})$

$\sigma_{r} \quad$ Total radial stress $(\mathrm{Pa})$

$\sigma_{\theta} \quad$ Total tangential stress $(\mathrm{Pa})$

$\tau_{1} \quad$ Maximum principal deviatoric stress $(\mathrm{Pa})$

$\tau_{2} \quad$ Intermediate principal deviatoric stress $(\mathrm{Pa})$

$\tau_{3} \quad$ Minimum principal deviatoric stress $(\mathrm{Pa})$

$\tau_{r} \quad$ Deviatoric radial stress $(\mathrm{Pa})$

$\tau_{\theta} \quad$ Deviatoric tangential stress $(\mathrm{Pa})$

$\tau^{*} \quad$ Deviatoric principal stress normalized by the maximum principal stress (Pa)

$\theta \quad$ Angle from maximum horizontal principal stress (radian)

\section{Appendix A. In-Situ Stress Data from Field Studies}

For the field cases studied, Table 1 gives a summary of the in-situ stresses, the rock failure properties and the type of Andersonian tectonics. The cases are briefly outlined below.

Woodland [4] analyzed drilling problems in shale formations of 450 wells in Western Canada, which were drilled after 1970 and were over $3048 \mathrm{~m}$ deep. The vertical, maximum and minimum horizontal stress gradients were determined respectively as $24.9 \pm 0.7,28.0$ and $19.2 \pm 1.4 \mathrm{kPa} / \mathrm{m}$ from density logging data, hydraulic fracture treatments and a minifrac test. Due to extremely low permeability of the shale formation critical for wellbore stability, direct measurement of the pore pressure was unfeasible [2]. Instead, the pore pressure gradient was assumed as $9.7 \mathrm{kPa} / \mathrm{m}$, based on analogy with the other drilling locations in Western Canada.

McLean and Addis [5] conducted a wellbore stability analysis and determined the vertical in-situ stress gradient of $22.6 \mathrm{kPa} / \mathrm{m}$ from the weight of overburden, the horizontal stress gradients were assumed to increase by $17.0 \mathrm{kPa} / \mathrm{m}$. The local rock properties, determined from test data, are a cohesion of $5.9 \mathrm{MPa}$, internal friction angle of $43.8^{\circ}$ and mean Poisson's ratio of 0.20 .

A wellbore stability analysis in the Mansouri oil field in Iran [6], located in a strike-slip fault regime, used density logs to estimate the vertical stress gradient of $25.3 \mathrm{kPa} / \mathrm{m}$, and the maximum and minimum horizontal stress gradients were 27.6 and $14.3 \mathrm{kPa} / \mathrm{m}$, based on empirical correlations in [40].

Ramos, et al. [7] analyzed the in-situ stress gradients in the Pagerungan Island gas field, Indonesia, by leak-off tests and wellbore breakout interpretation. From the leak-off tests in two wells, the maximum and minimum horizontal stress gradients were 27.6 and $19.7 \mathrm{kPa} / \mathrm{m}$, respectively. According to the breakout interpretation, the horizontal stresses vary from layer to layer. The results show that the vertical, maximum and minimum horizontal stress gradients are 22.6, 20.4-28.7, and $15.8-19.5 \mathrm{kPa} / \mathrm{m}$, respectively. From a set of laboratory tests on lamination-free specimens, the cohesion, internal friction angle and Poisson's ratio of the rock were determined as 12.4 $\mathrm{MPa}, 35.0^{\circ}$ and 0.20 , respectively.

Analyzing wellbore breakouts and injection tests, Onaisi, et al. [8] determined the in-situ stresses in the ABK field, offshore Abu-Dhabi. The gradients of vertical, maximum and minimum horizontal stresses are 22.6, 34.4 , and $24.4 \mathrm{kPa} / \mathrm{m}$, respectively. The authors also performed a set of differential strain analysis tests using core specimens, but concluded that the testing results were not reliable for in-situ stress determination. The rock properties from laboratory tests showed that the unconfined compressive strength (UCS), internal friction angle and Poisson's ratio are $5.5 \mathrm{MPa}, 50.2^{\circ}$ and 0.30 , respectively.

Awal, et al. [9] analyzed the instability problems for two offshore wells in the Arabian Gulf. The vertical, maximum and minimum horizontal stress gradients are $24.9,22.6$, and $20.4 \mathrm{kPa} / \mathrm{m}$. Although the authors did not specify the measurement method for the rock mechanical properties, the parameters used for the wellbore stability analysis are the cohesion of $6.0 \mathrm{MPa}$ and the internal friction angle of $31.3^{\circ}$.

Focusing on the effect of the bedding plane slippage on well stability, Willson, et al. [10] analyzed an appraisal well in the Cusiana field, Colombia, in which the maximum horizontal stress is greater than the overburden stress. The gradients of the vertical, maximum, minimum horizontal stresses, and the pore pressure are 24.4, 30.8, 17.0, 
and $9.5 \mathrm{kPa} / \mathrm{m}$, respectively. In the same field, the in-situ stresses and pore pressure gradients were measured during drilling [11]. The results show that the vertical, maximum, minimum horizontal stresses and the pore pressure have the gradients of $24.9,31.7,15.8$, and $10.0 \mathrm{kPa} / \mathrm{m}$, respectively.

\section{Appendix B. Converting Non-Dimensional Stress Trajectory Scalars Using Dimensional Total Stress Inputs}

Practical wellbore stability analysis commonly uses dimensional data collected from wellbore logs and other sources, such as the total principal stresses for a specific drilling location. The brief sections below outline how certain non-dimensional scalars $(F, \chi)$, previously introduced to characterize stress trajectory patterns around wellbores using deviatoric stress only [2,26], can be converted for use with dimensional, total stress inputs. The Kirsch equations are strictly formulated for the two principal stresses in the plane normal to the wellbore, and below derivations show that one needs to be specific about which of the two from the 3D stress state are used. Kirsch [41] assumed a thin plate theory with zero stress normal to the plate. When the 2D solution are applied, one needs to be specific about the state of stress parallel to the wellbore as occurring in the subsurface.

\section{Appendix B.1. Stress Trajectory Scalars Expressed in Deviatoric Stress}

Recent studies $[2,33]$ have highlighted the systematic variation of stress trajectory patterns around wellbores due to the relative magnitude of the internal net pressure on the wellbore and a uniaxial far-field stress. Stress trajectory patterns near a wellbore subjected to any deviatoric far-field stress can be characterized by the Frac number [2], defined by the ratio of the net pressure, $P_{N E T}$, on the wellbore, and the absolute magnitude of the largest far-field deviatoric stress $\left|\tau_{1}\right|$, as first given in Weijermars, Zhang and Schultz-Ela [2]:

$$
F=\frac{P_{N E T}}{\left|\tau_{1}\right|}
$$

For cases where the maximum principal stress is not in the plane of study, but parallel to the wellbore, it may be more practical to normalize $P_{N E T}$ instead by another appropriate principal stress as follows:

$$
F_{i}=\frac{P_{N E T}}{\left|\tau_{j}\right|}
$$

The subscript $i$ indicates the principal stress that the wellbore is aligned with. For a vertical wellbore, the subscript $i$ in the compressional, strike-slip and extensional basins is either 3, 2, or 1, respectively. Subscript $j=1$, when $i=3$ or 2 . However, for $i=1$ (such as for a vertical wellbore in an extensional basin) we prefer using $j=2$ (see Appendix B.5), because the principal stresses in the plane normal to the wellbore are $\tau_{2}$ and $\tau_{3}$. For a perfect Andersonian extension $\tau_{2}=0$ and $\tau_{3}=-\tau_{1}$, which is why normalization by $\tau_{1}$ in Equation (A1b) is warranted for such cases. Positive Frac numbers characterize overpressured wellbores with stress cage effects, and negative Frac numbers with fracture cage effects occur for underbalanced wellbores [33].

The stress trajectory patterns described in the Kirsch equations may either be due to a uniaxial deviatoric stress state, or a bi-axial deviatoric stress state as detailed in [1]. The latter study introduced a second non-dimensional scalar, $\chi$, named the Bi-axial Stress scalar, to characterize the far-field deviatoric stress in the plane of study:

$$
\chi=\frac{-\tau_{3}}{\left|\tau_{1}\right|}
$$

One implied assumption in our prior studies [1,26] is that $\tau_{1}$ and $\tau_{3}$ are considered to act in the plane perpendicular to the wellbore, and $\tau_{2}$ assumed parallel to the wellbore. However, for practical situations such as vertical and horizontal wellbores, one of the two other principal stresses $\left(\tau_{1}\right.$ or $\left.\tau_{3}\right)$ may be aligned with the wellbore, rather than $\tau_{2}$. For such case, we modify expression (A1c) as follows:

$$
\chi_{i}=\frac{-\tau_{k}}{\left|\tau_{j}\right|}
$$

At all times, the value $(1,2$, or 3$)$ of subscript $j$ should be identical to the one used for normalization of $P_{N E T}$ used in Equation (A1b), because each pair of $(F, \chi)$ values solves the Kirsch equations for the radial and tangential stresses $\left(\tau_{r}, \tau_{\theta}\right)$, which can be translated to dimensional stress multiplying each value by $\tau_{k}$ (duly observing for any undue sign switches; see details in Appendix A of [1]). The subscripts $i, j, k$ in Equation (A1d) will differ for the compressional, strike-slip and extensional basins, with $i$ indicating the direction of the wellbore, and $j$ and $k$ are the appropriate complementary principal stress axes in the plane of study. For example, a vertical wellbore in compressional, strike-slip and extensional basins, will have the indices $(i, j, k)$ as follows: $(3,1,2),(2,1,3)$ and $(1,2,3)$, respectively. When the wellbore is horizontal, the indices switch accordingly. For plane stress, $\chi=1$, and for uniaxial stress, $\chi=0$, with $\chi$ expressing both end members and any intermediate state of far-field deviatoric 
stress. The merit of using the non-dimensional scaling parameters is that each $(F, \chi)$ pair of values corresponds to a unique stress trajectory pattern as has been mapped out in detail elsewhere $[1,26]$.

Expressions to compute $(F, \chi)$ values and compare the stress trajectories for any 3D stress state are specified below in terms of total stress inputs for practical conversion to deviatoric stresses, assuming the wellbore remains aligned with an arbitrary principal stress axis.

\section{Appendix B.2. Conversion of Deviatoric Stresses to Total Stresses}

For practical wellbore stability analysis, stress and pressure inputs are commonly available as dimensional quantities, which prompted us to reformulate the stress trajectory scalars $(F, \chi)$ in terms of total stress rather than deviatoric stress. In order to do so, we must first explain how the total stress tensor elements, $\sigma_{i j}$, relate to the deviatoric stress tensor elements, $\tau_{i j}$, and local confining pressure, $P$ :

$$
\sigma_{i j}=\tau_{i j}+P
$$

A distinction can be made for strictly Andersonian far-field stress states, which are limited to plane 2D deviatoric stress, i.e., $\tau_{2}=0$, and cases without any such constraints, so that $3 \mathrm{D}$ deviatoric stress may exist. For the 2D deviatoric stress states, $P=\sigma_{2}$, so that the local pressure is uniquely given by averaging just two principal total stresses in the directions where deviatoric stresses do not vanish:

$$
P=\sigma_{\text {mean }}=\frac{\left(\sigma_{1}+\sigma_{3}\right)}{2}
$$

For the 3D deviatoric stress states, $P$ is again the average of the three principal total stresses, but no simplification is possible, all three principal stresses need to be taken into account to compute the local confining pressure:

$$
P=\sigma_{\text {mean }}=\frac{\left(\sigma_{1}+\sigma_{2}+\sigma_{3}\right)}{3}
$$

Equations (A2)-(A3b) are useful when we need to express the stress trajectory scalars $(F, \chi)$ in terms of total stress rather than deviatoric stress, for which we distinguish 2D (Supplementary Materials) and 3D deviatoric stress cases (Supplementary Materials). An additional expression useful for our conversion of deviatoric and total stresses is that the sum of the three principal, deviatoric stresses always needs to be zero, as can be verified from:

$$
\tau_{1}+\tau_{2}+\tau_{3}=\left(\sigma_{1}-P\right)+\left(\sigma_{2}-P\right)+\left(\sigma_{3}-P\right)
$$

Substituting Equation (A3b) into Equation (A4a) gives:

$$
\tau_{1}+\tau_{2}+\tau_{3}=0
$$

In contrast, total stresses (if not purely deviatoric) do never sum to zero, but are equal to $3 P$ as per Equation (A3b). Separately, Equation (A4a) confirms that when the intermediate deviatoric stress vanishes $\left(\tau_{2}=0\right)$ (as for the strict Andersonian cases), the deviatoric stress in the $\tau_{1}, \tau_{3}$-plane will be in a plane stress state $\left(\tau_{1}=-\tau_{3}\right)$, which occurs when $\chi=1$ [cf. Equation (A1)]. However, for uniaxial deviatoric stress $(\chi=0)$, with $\tau_{1}>0$ and $\tau_{3}=0$, it follows $\tau_{2}<0$ (from Equation (A5b), which violates the ranking convention of the stress tensor elements $\left(\tau_{1} \geq \tau_{2} \geq \tau_{3}\right)$. Correcting the ordering means $\tau_{1}>0$ and $\tau_{3}<0$ and $\tau_{2}=0$. Consequently, what was assumed to be a wellbore// $\tau_{2}$, is in fact $/ / \tau_{3}$. For such cases, we must use the definition of $\chi_{3}$ in terms of total stresses (see Appendix B.5). Extension occurs in the direction of the wellbore and may cause transverse fractures.

\section{Appendix B.3. Stress Trajectory Scalars Expressed in Total Stress: 2D Deviatoric (= Plane) Stress Cases}

Deviatoric stress acting only in two dimensions, (i.e., $\tau_{2}=0$ ), is defined as follows:

$$
\tau_{1,3}=\sigma_{1,3}-P
$$

In the 2D analysis we can substitute Equation (A3a) for the pressure into Equation (A5a) and solve for deviatoric stress as a function of total stresses only:

$$
\tau_{1,3}=\sigma_{1,3}-\frac{\left(\sigma_{1}+\sigma_{3}\right)}{2}
$$


Substituting Equation (A5b) into Equation (A1c) gives and expression for $\chi$ in terms of total stresses (2D case):

$$
\chi_{2}=\frac{-\left(\sigma_{3}-\frac{\left(\sigma_{1}+\sigma_{3}\right)}{2}\right)}{\left|\sigma_{1}-\frac{\left(\sigma_{1}+\sigma_{3}\right)}{2}\right|}=\frac{\sigma_{1}-\sigma_{3}}{\left|\left(\sigma_{1}-\sigma_{3}\right)\right|}
$$

Subscript 2 denotes $\chi$ is given for a case with the wellbore parallel to the intermediate principal stress axis. The numerator and denominator in Equation (A6) for a 2D plane stress will always be equal in magnitude, and, because per definition $\sigma_{1}>\sigma_{3}$, the numerator and denominator will always have the same sign, which means the $\chi$ value will always be 1 . This result is obvious, because $2 \mathrm{D}$ deviatoric stress in a plane stress state requires that $\tau_{1}=-\tau_{3}$, which means expression (2) also will always be 1, consistent with the outcome of Equation (A6). When using total stresses from a Mechanical Earth Model (MEM), the native state of stress can be characterized using $\chi_{2}$ from Equation (A6). For $\chi_{2}=1$, the occurrence of plane deviatoric state is confirmed [i.e., $\tau_{2}=0$ and $\sigma_{2}=P$ ], and validity of Equation (A3a)]. However, Equation (A6) is only valid for plane stress $\left(\chi_{2}=1\right)$ and when instead $\tau_{2} \neq 0$, we need to switch to using the 3D expression for $\chi$ given in Appendix B.4.

\section{Appendix B.4. Intermediate Principal 3D Stress Parallel to Wellbore}

We next examine the stress trajectory scalars expressed in total stress for 3D deviatoric stress cases. When deviatoric stress occurs in three dimensions, the deviators acting in the $\tau_{1}, \tau_{3}$-plane normal to the wellbore given by Equation (A5a) is still valid:

$$
\tau_{1,3}=\sigma_{1,3}-P
$$

In the $3 \mathrm{D}$ analysis we can substitute Equation $(\mathrm{A} 4 \mathrm{~b})$ for the pressure into Equation (A7a) and solve for deviatoric stress as a function of total stresses only:

$$
\tau_{1,3}=\sigma_{1,3}-\frac{\left(\sigma_{1}+\sigma_{2}+\sigma_{3}\right)}{3}
$$

Substituting Equation (A7b) into Equation (A1) for $\chi$ denoted by subscript 2 for $\chi$ so we know $\chi_{2}$ is given for a case with the wellbore parallel to the intermediate stress principal stress axis (3D case):

$$
\chi_{2}=\frac{-\left(\sigma_{3}-\frac{\left(\sigma_{1}+\sigma_{2}+\sigma_{3}\right)}{3}\right)}{\left|\sigma_{1}-\frac{\left(\sigma_{1}+\sigma_{2}+\sigma_{3}\right)}{3}\right|}=\frac{\sigma_{1}+\sigma_{2}-2 \sigma_{3}}{\left|2 \sigma_{1}-\sigma_{2}-\sigma_{3}\right|}
$$

We can substitute a limiting case of $\sigma_{1}=\sigma_{2}$ into Equation (A8a) which gives $\chi_{2}=2$ as the maximum value. For this case $\left(\chi_{2}=2\right)$, the deviatoric stress $\tau_{1}=\tau_{2}$ (both having a positive sign), which is a uniform radial compression in the $\tau_{1}, \tau_{2}$-plane, using Equation (A4b) with the stated condition gives $\tau_{3}=-2 \tau_{1}$, which corresponds to $\chi_{2}=2$. Other possible cases for $\sigma_{1}$ and $\sigma_{2}$ both being positive and larger than $P$, means $\tau_{1}$ and $\tau_{2}$ both being positive so in the observational plane normal to the wellbore $\tau_{1} \leq-0.5 \tau_{3}$, which will occur for $1 \leq \chi_{2} \leq 2, \tau_{1}$ and $\tau_{2}$ both being positive and so that $\tau_{3}<0$. Applying Equation (A4b), we can conclude $\tau_{2}=\tau_{3}$ (both having a positive sign), which is a uniform radial constriction in the $\tau_{1}, \tau_{2}$-plane. Our previous work $[1,26]$ stated $\chi$ would never exceed 1 . Cases with $0 \leq \tau_{2} \leq \tau_{1}$ corresponding to a range for $\chi_{2}$ between 1 and 2 , which occur when some form of radial constriction exists in the $\tau_{1}, \tau_{2}$-plane, were not considered. Values of $\chi_{2}$ - cannot exceed 2, because any $\tau_{3}>-2 \tau_{1}$ would require [applying Equation (A4b)] that $\tau_{2}>\tau_{1}$, which would be counter to the agreed convention of principal stress ranking according to $\tau_{1} \geq \tau_{2} \geq \tau_{3}$. The lower limit is obtained when $\sigma_{1}>\sigma_{2}=\sigma_{3}$, which gives $\chi_{2}=0.5$.

Since $\tau_{2}$ is defined as the stress that is parallel to the wellbore, $\sigma_{2}$ is also parallel to the wellbore, and being the intermediate stress, must be greater than (or equal to) $\sigma_{3}$ and smaller than (or equal to) $\sigma_{1}$. Also, note that for the $2 \mathrm{D}$ deviatoric case, $P=\sigma_{2}$, so that we can substitute in Equation (A8a) $\sigma_{2}=P=\left(\sigma_{1}+\sigma_{3}\right) / 2$, which gives (2D case):

$$
\chi_{2}=\frac{\sigma_{1}+\sigma_{2}-2 \sigma_{3}}{\left|2 \sigma_{1}-\sigma_{2}-\sigma_{3}\right|}=\frac{3 \sigma_{1}-3 \sigma_{3}}{\left|3 \sigma_{1}-3 \sigma_{3}\right|}
$$

As to be expected expression (A8b) is identical to Equation (A6). For completeness, the Frac number of Equation (A1b) is here expressed in terms of total stress. First we express $\tau_{1}$ in terms of total stress:

$$
\tau_{1}=\sigma_{1}-P=\sigma_{1}-\frac{\left(\sigma_{1}+\sigma_{2}+\sigma_{3}\right)}{3}=\frac{2 \sigma_{1}-\sigma_{2}-\sigma_{3}}{3}
$$

Next we substitute Equation (A9) into Equation (A1b) to obtain:

$$
F_{2}=\frac{3 P_{N E T}}{\left|2 \sigma_{1}-\sigma_{2}-\sigma_{3}\right|}
$$


Jointly, the scaling parameters $\left(F_{2}, \chi_{2}\right)$ characterize a particular stress trajectory pattern given in terms of total stress by Equations (A10) and (A8a), respectively, and representative solutions have been illustrated in Thomas and Weijermars [1].

\section{Appendix B.5. Largest Principal 3D Stress Parallel to Wellbore}

Using pairs of $(F, \chi)$ corresponds to a unique stress trajectory pattern [1] and an implied assumption is that $\tau_{1}$ and $\tau_{3}$ are considered to act in the plane perpendicular to the wellbore, so those previous cases are valid for $\left(F_{2}, \chi_{2}\right)$ introduced in the present study. When we have instead $\tau_{2}$ and $\tau_{3}$ acting in the plane normal to the wellbore, the Kirsch equations should be normalized with $\left(F_{1}, \chi_{1}\right)$ values, by first adjusting Equations (A1b) and (A1d) using $\tau_{2}$ and $\tau_{3}$, as follows:

$$
\begin{aligned}
& F_{1}=\frac{P_{N E T}}{\left|\tau_{2}\right|} \\
& \chi_{1}=\frac{-\tau_{3}}{\left|\tau_{2}\right|}
\end{aligned}
$$

The corresponding expression using total principal stress inputs are:

$$
\begin{aligned}
& F_{1}=\frac{3 P_{N E T}}{\left|-\sigma_{1}+2 \sigma_{2}-\sigma_{3}\right|} \\
& \chi_{1}=\frac{\sigma_{1}+\sigma_{2}-2 \sigma_{3}}{\left|-\sigma_{1}+2 \sigma_{2}-\sigma_{3}\right|}
\end{aligned}
$$

This situation may arise in vertical wellbores placed in nearly perfect extensional as well as transtensional zones. Note that perfect extension is not permitted due to requirement for Equations (A11a,b) that $\tau_{2} \neq 0$. Also, cases where $\tau_{1}$ and $\tau_{3}$ are both negative is not permissible due to the tensor ranking $\left(\tau_{1} \geq \tau_{2} \geq \tau_{3}\right)$ and condition $\tau_{1}+\tau_{2}+\tau_{3}=0$. Instead, $\tau_{1} \geq 0$ and $\tau_{2}$ and $\tau_{3}$ may both be negative. This situation may give rise to $1 \leq \chi_{1} \leq \infty$. An alternative scaling for $\left(F_{1}, \chi_{1}\right)$ would be to normalize both values by $\left|\tau_{3}\right|$, such that $F_{1}=P_{N E T} /\left|\tau_{3}\right|$ and $\chi_{1}=-\tau_{2} /\left|\tau_{3}\right|$, which for a vertical wellbore in a perfect extensional basin effectively means $\left|\tau_{3}\right|=\left|\tau_{1}\right|$ such that $\chi_{1}=-\tau_{3} /\left|\tau_{1}\right|$. This option was not pursued in our present study.

\section{Appendix B.6. Minimum Principal 3D Stress Parallel to Wellbore}

Similarly, when we have instead $\tau_{1}$ and $\tau_{2}$ in the plane normal to the wellbore, the Kirsch equations should be normalized with $\left(F_{3}, \chi_{3}\right)$ values, adjusting Equations (A1b) and (A1d) using $\tau_{1}$ and $\tau_{2}$, as follows:

$$
\begin{gathered}
F_{3}=\frac{P_{N E T}}{\left|\tau_{1}\right|} \\
\chi_{3}=\frac{-\tau_{2}}{\left|\tau_{1}\right|}
\end{gathered}
$$

The corresponding expression in total stresses are:

$$
\begin{aligned}
& F_{3}=\frac{3 P_{N E T}}{\left|2 \sigma_{1}-\sigma_{2}-\sigma_{3}\right|} \\
& \chi_{3}=\frac{\sigma_{1}-2 \sigma_{2}+\sigma_{3}}{\left|2 \sigma_{1}-\sigma_{2}-\sigma_{3}\right|}
\end{aligned}
$$

This situation may arise in vertical wellbores placed in transpressional zones, for which case the $\chi_{3}$ value is limited between $-1 \leq \chi_{3} \leq 0.5$, as in the example for the Andersonian reverse faulting case given in the main text. A special case occurs when $\sigma_{2}=\sigma_{3}$, for which $\chi_{3}$ will be 0 , characterizing the far field stress to be uniaxial in the plane normal to $\sigma_{3}$.

The Frac number, for all cases considered, ranges $-\infty \leq F_{1,2,3} \leq \infty$. The characterization of the in situ stress in the plane of analysis normal to the wellbore by $\chi$ may attain different ranges for the various cases (see Table A1). 
Table A1. Summary of $(F, \chi)$ values used for total stress inputs.

\begin{tabular}{lccccc}
\hline \multicolumn{2}{l}{ Orientation Wellbore } & \multicolumn{2}{c}{ Expressions to be Used } & \multicolumn{2}{c}{ Value Range } \\
\hline Vertical & Horizontal & $\boldsymbol{F}$ Values & $\chi$ Values & $\boldsymbol{F}$ & $\chi$ \\
\hline$/ / \sigma_{1}$ & $/ / \sigma_{1}$ & $F_{1}=\frac{3 P_{N E T}}{\left|-\sigma_{1}+2 \sigma_{2}-\sigma_{3}\right|}$ & $\chi_{1}=\frac{\sigma_{1}+\sigma_{2}-2 \sigma_{3}}{\left|-\sigma_{1}+2 \sigma_{2}-\sigma_{3}\right|}$ & $-\infty \leq F_{1} \leq+\infty$ & $1 \leq \chi_{1} \leq \infty$ \\
\hline$/ / \sigma_{2}$ & $/ / \sigma_{2}$ & $F_{2}=\frac{3 P_{N E T}}{\left|2 \sigma_{1}-\sigma_{2}-\sigma_{3}\right|}$ & $\chi_{2}=\frac{\sigma_{1}+\sigma_{2}-2 \sigma_{3}}{\left|2 \sigma_{1}-\sigma_{2}-\sigma_{3}\right|}$ & $-\infty \leq F_{2} \leq+\infty$ & $0.5 \leq \chi_{2} \leq 2$ \\
\hline$/ / \sigma_{3}$ & $/ / \sigma_{3}$ & $F_{3}=\frac{3 P_{N E T}}{\left|2 \sigma_{1}-\sigma_{2}-\sigma_{3}\right|}$ & $\chi_{3}=\frac{\sigma_{1}-2 \sigma_{2}+\sigma_{3}}{\left|2 \sigma_{1}-\sigma_{2}-\sigma_{3}\right|}$ & $-\infty \leq F_{3} \leq+\infty$ & $-1 \leq \chi_{3} \leq 0.5$ \\
\hline
\end{tabular}

\section{Appendix B.7. Summary of Inputs and Non-Dimensionalization Algorithms to be used in our Methodology}

The summary Table A1 shows the stress states and definitions of $(F, \chi)$ values used for total stress inputs, depending on which of the three principal stress axes is aligned with the wellbore.

The various design solutions for fracture treatments of horizontal and vertical wellbores in basins with Andersonian native stress states have been highlighted in appendix B of Thomas and Weijermars [1]. For practical applications it is highly recommended that Table A1 in the present study be used in conjunction with tables A1 and $\mathrm{A} 2$ given in the cited study.

\section{Appendix C. Analysis of Stresses Around Wellbore}

\section{Appendix C.1. Deviatoric Stresses Around Wellbore}

Once a wellbore is drilled in a formation and is filled with drilling fluid, the principal stress magnitudes and trajectories around the wellbore are redistributed. The stress conditions are normally calculated by the Kirsch equations, which was initially proposed to analytically model the stress around the circular hole around the plate. Due to its simplicity and straightforwardness, the equations have been widely used for various field applications [2,42]. Instead of using the total stresses, Weijermars [25] proposed a new approach in determination of stresses around the wellbore using the deviatoric stress concept with an emphasis that the shape deformation and the rock failure are directly related with the deviatoric stresses. The Kirsch equations can be derived from an Airy stress function in cylindrical coordinates and be expressed with the deviatoric stresses [1,2]. The radial, tangential, and shear deviatoric stresses around the wellbore are calculated from the equations as follows.

$$
\begin{gathered}
\tau_{r}=P_{N E T} \frac{a^{2}}{r^{2}}+\frac{1}{2}\left(\tau_{1}+\tau_{3}\right)\left(1-\frac{a^{2}}{r^{2}}\right)+\frac{1}{2}\left(\tau_{1}-\tau_{3}\right)\left(1-4 \frac{a^{2}}{r^{2}}+3 \frac{a^{4}}{r^{4}}\right) \cos 2 \theta \\
\tau_{\theta}=-P_{N E T} \frac{a^{2}}{r^{2}}+\frac{1}{2}\left(\tau_{1}+\tau_{3}\right)\left(1+\frac{a^{2}}{r^{2}}\right)-\frac{1}{2}\left(\tau_{1}-\tau_{3}\right)\left(1+3 \frac{a^{4}}{r^{4}}\right) \cos 2 \theta \\
\tau_{r \theta}=-\frac{1}{2}\left(\tau_{1}-\tau_{3}\right)\left(1+2 \frac{a^{2}}{r^{2}}-3 \frac{a^{4}}{r^{4}}\right) \sin 2 \theta
\end{gathered}
$$

where, $\tau_{1}$ and $\tau_{3}$ are the maximum and minimum in-situ principal deviatoric stresses normal to the wellbore, $a$ is the wellbore radius, $r$ is the distance from the wellbore center and $\theta$ is the angle from the maximum principal stress direction. Readers should note that the subscription 1 and 3 need to be properly changed in accordance with the plane normal to the wellbore.

Dividing Equations (A15a-c) by the maximum deviatoric principal stress normal to the wellbore, the deviatoric stresses around the wellbore in cylindrical coordinates can be expressed with $\tau_{1}$-normalized dimensionless forms. The readers should note that the absolute value, $\left|\tau_{1}\right|$, was used in calculation to avoid confusions in sign conventions.

$$
\begin{gathered}
\tau_{r}^{*}=\frac{\tau_{r}}{\tau_{1}}=F_{i} c^{2}+\frac{1}{2}\left(1-\chi_{i}\right)\left(1-c^{2}\right)+\frac{1}{2}\left(1+\chi_{i}\right)\left(1-4 c^{2}+3 c^{4}\right) \cos 2 \theta \\
\tau_{\theta}^{*}=\frac{\tau_{\theta}}{\tau_{1}}=-F_{i} c^{2}+\frac{1}{2}\left(1-\chi_{i}\right)\left(1+c^{2}\right)-\frac{1}{2}\left(1+\chi_{i}\right)\left(1+3 c^{4}\right) \cos 2 \theta \\
\tau_{r \theta}{ }^{*}=\frac{\tau_{r \theta}}{\tau_{1}}=-\frac{1}{2}\left(1+\chi_{i}\right)\left(1+2 c^{2}-3 c^{4}\right) \sin 2 \theta
\end{gathered}
$$

where, $i$ is 1,2 , or 3 for the normal faulting, strike-slip and reverse faulting regimes, respectively. In addition, the maximum principal deviatoric stress is $\tau_{1}$, except for the normal faulting regime $\left(\tau_{2}\right)$. Therefore, the deviatoric stress distribution around the wellbore solely depends on the $F$ and $\chi$. 


\section{Appendix C.2. Stress Magnitude and Trajectory in Cartesian Coordinates}

In order to quantify the principal stresses in the Cartesian coordinates, the following tensor transformation can be used.

$$
\left[\begin{array}{ll}
\tau_{x x}^{*} & \tau_{x y}^{*} \\
\tau_{y x} & \tau_{y y}
\end{array}\right]=\left[\begin{array}{cc}
\cos \theta & -\sin \theta \\
\sin \theta & \cos \theta
\end{array}\right]\left[\begin{array}{cc}
\tau_{r}^{*} & \tau_{r \theta} \theta^{*} \\
\tau_{\theta r}^{*} & \tau_{\theta}^{*}
\end{array}\right]\left[\begin{array}{cc}
\cos \theta & \sin \theta \\
-\sin \theta & \cos \theta
\end{array}\right]
$$

Then, the stress condition can to be transformed into the Cartesian coordinates by the following equations,

$$
\begin{gathered}
\tau_{x x}{ }^{*}=\frac{1}{2} \tau_{r}^{*}(1+\cos 2 \theta)-\tau_{r \theta}{ }^{*} \sin 2 \theta+\frac{1}{2} \tau_{\theta}{ }^{*}(1-\cos 2 \theta) \\
\tau_{y y}{ }^{*}=\frac{1}{2} \tau_{r}^{*}(1-\cos 2 \theta)+\tau_{r \theta}{ }^{*} \sin 2 \theta+\frac{1}{2} \tau_{\theta}{ }^{*}(1+\cos 2 \theta) \\
\tau_{x y}{ }^{*}=\frac{1}{2}\left(\tau_{r}^{*}-\tau_{\theta}{ }^{*}\right) \sin 2 \theta+\tau_{r \theta}{ }^{*} \cos 2 \theta
\end{gathered}
$$

The magnitudes of the deviatoric principal stresses can be obtained by,

$$
\begin{aligned}
& \tau_{1}=\frac{1}{2}\left(\tau_{x x}{ }^{*}+\tau_{y y}{ }^{*}\right)+\sqrt{\left(\tau_{x y}\right)^{2}+\frac{1}{4}\left(\tau_{x x}{ }^{*}-\tau_{y y}\right)^{2}} \\
& \tau_{3}=\frac{1}{2}\left(\tau_{x x}{ }^{*}+\tau_{y y}{ }^{*}\right)-\sqrt{\left(\tau_{x y}\right)^{2}+\frac{1}{4}\left(\tau_{x x^{*}}-\tau_{y y}\right)^{2}}
\end{aligned}
$$

In addition, the trajectories of the principal stresses can be determined by the inclination, $\beta$, given by,

$$
\beta=\frac{1}{2} \tan ^{-1}\left(\frac{2 \tau_{x y}{ }^{*}}{\tau_{x x^{*}}-\tau_{y y}{ }^{*}}\right)
$$

The two conjugate solutions for $\beta$ are separated by $\pi / 2$. In order to outline the full trajectories of the principal stresses, continuous solutions can be drawn by any commercial programming software. The trajectories contain important characteristics of potential instability near the wellbore. Since induced tensile fractures will always propagate in the direction of the maximum principal stress, the reliably determined trajectory provides useful information in prediction of the direction of the induced fracture propagation and of potential location of the instability.

\section{References}

1. Thomas, N.; Weijermars, R. Comprehensive atlas of stress trajectory patterns and stress magnitudes around cylindrical holes in rock bodies for geoscientific and geotechnical applications. Earth-Sci. Rev. 2018, 179, 303-371. [CrossRef]

2. Weijermars, R.; Zhang, X.; Schultz-Ela, D. Geomechanics of fracture caging in wellbores. Geophys. J. Int. 2013, 193, 1119-1132. [CrossRef]

3. Peng, S.; Zhang, J. Engineering Geology for Underground Rocks; Springer: Berlin/Heidelberg, Germany; New York, NY, USA, 2007.

4. Woodland, D.C. Borehole instability in the Western Canadian overthrust belt. SPE Drill. Eng. 1990, 5, 27-33. [CrossRef]

5. McLean, M.R.; Addis, M.A. Wellbore stability: The effect of strength criteria on mud weight recommendations. In SPE Annual Technical Conference and Exhibition; Society of Petroleum Engineers: New Orleans, LA, USA, 1990.

6. Saberhosseini, S.E.; Ahangari, K.; Alidoust, S. Stability analysis of a horizontal oil well in a strike-slip fault regime. Aust. J. Earth Sci. 2013, 106, 137-143.

7. Ramos, G.G.; Mouton, D.E.; Wilton, B.S. Integrating rock mechanics with drilling strategies in a tectonic belt, offshore Bali, Indonesia. In Proceedings of the SPE/ISRM Rock Mechanics in Petroleum Engineering, Trondheim, Norway, 8-10 July 1998; Society of Petroleum Engineers: Richardson, TX, USA, 1998.

8. Onaisi, A.; Locane, J.; Razimbaud, A. Stress related wellbore instability problems in deep wells in ABK field. In Proceedings of the Abu Dhabi International Petroleum Exhibition and Conference, Abu Dhabi, UAE, 13-15 October 2000; Society of Petroleum Engineers: Richardson, TX, USA, 2000. 
9. Awal, M.R.; Khan, M.S.; Mohiuddin, M.A.; Abdulraheem, A.; Azeemuddin, M. A new approach to borehole trajectory optimisation for increased hole stability. In Proceedings of the SPE Middle East Oil Show, Manama, Bahrain, 17-20 March 2001; Society of Petroleum Engineers: Richardson, TX, USA, 2001.

10. Willson, S.M.; Last, N.C.; Zoback, M.D.; Moos, D. Drilling in South America: A wellbore stability approach for complex geologic conditions. In Proceedings of the Latin American and Caribbean Petroleum Engineering Conference, Caracas, Venezuela, 27-29 April 1994; Society of Petroleum Engineers: Richardson, TX, USA, 1999.

11. Last, N.C.; McLean, M.R. Assessing the impact of trajectory on wells drilled in an overthrust region. J. Pet. Technol. 1996, 48, 620-626. [CrossRef]

12. Al-Ajmi, A.M.; Zimmerman, R.W. Stability analysis of vertical boreholes using the Mogi-Coulomb failure criterion. Int. J. Rock Mech. Min. Sci. 2006, 43, 1200-1211. [CrossRef]

13. Ewy, R.T. Wellbore-stability predictions by use of a modified Lade criterion. SPE Drill. Complet. 1999, 14, 85-91. [CrossRef]

14. Gholami, R.; Moradzadeh, A.; Rasouli, V.; Hanachi, J. Practical application of failure criteria in determining safe mud weight windows in drilling operations. J. Rock Mech. Geotech. Eng. 2014, 6, 13-25. [CrossRef]

15. Maleki, S.; Gholami, R.; Rasouli, V.; Moradzadeh, A.; Riabi, R.G.; Sadaghzadeh, F. Comparison of different failure criteria in prediction of safe mud weigh window in drilling practice. Earth-Sci. Rev. 2014, 136, 36-58. [CrossRef]

16. Meyer, J.P.; Labuz, J.F. Linear failure criteria with three principal stresses. Int. J. Rock Mech. Min. Sci. 2013, 60, 180-187. [CrossRef]

17. Makhnenko, R.Y.; Harvieux, J.; Labuz, J.F. Paul-Mohr-Coulomb failure surface of rock in the brittle regime. Geophys. Res. Lett. 2015, 42, 6975-6981. [CrossRef]

18. Al-Ajmi, A.M.; Zimmerman, R.W. A new well path optimization model for increased mechanical borehole stability. J. Pet. Sci. Eng. 2009, 69, 53-62. [CrossRef]

19. Zhang, L.; Cao, P.; Radha, K.C. Evaluation of rock strength criteria for wellbore stability analysis. Int. J. Rock Mech. Min. Sci. 2010, 47, 1304-1316. [CrossRef]

20. Fontoura, S. Lade and Modified Lade 3D Rock Strength Criteria. Rock Mech. Rock Eng. 2012, 45, 1001-1006. [CrossRef]

21. Ma, T.; Chen, P.; Yang, C.; Zhao, J. Wellbore stability analysis and well path optimization based on the breakout width model and Mogi-Coulomb criterion. J. Pet. Sci. Eng. 2015, 135, 678-701. [CrossRef]

22. Mansourizadeh, M.; Jamshidian, M.; Bazargan, P.; Mohammadzadeh, O. Wellbore stability analysis and breakout pressure prediction in vertical and deviated boreholes using failure criteria-A case study. J. Pet. Sci. Eng. 2016, 145, 482-492. [CrossRef]

23. Das, B.; Chatterjee, R. Wellbore stability analysis and prediction of minimum mud weight for few wells in Krishna-Godavari Basin, India. Int. J. Rock Mech. Min. Sci. 2017, 93, 30-37. [CrossRef]

24. Abbasi, S.; Singh, R.K.; Singh, K.H.; Singh, T.N. Selection of failure criteria for estimation of safe mud weights in a tight gas sand reservoir. Int. J. Rock Mech. Min. Sci. 2018, 107, 261-270. [CrossRef]

25. Weijermars, R. Analytical stress functions applied to hydraulic fracturing: Scaling the interaction of tectonic stress and unbalanced borehole pressures. In Proceedings of the 45th U.S. Rock Mechanics/Geomechanics Symposium, San Francisco, CA, USA, 26-29 June 2011; American Rock Mechanics Association: Alexandria, VA, USA, 2011.

26. Thomas, N. Visualizing Wellbore Instability and Planes of Failure in Boreholes by Application of Principal Stress Trajectory Analysis. Master's Thesis, Texas A\&M University, College Station, TX, USA, 2017.

27. Alberty, M.W.; McLean, M.R. A Physical Model for Stress Cages. In Proceedings of the SPE Annual Technical Conference and Exhibition, Houston, TX, USA, 26-29 September 2004; Society of Petroleum Engineers: Richardson, TX, USA, 2004.

28. Chang, C.; Zoback, M.D.; Khaksar, A. Empirical relations between rock strength and physical properties in sedimentary rocks. J. Pet. Sci. Eng. 2006, 51, 223-237. [CrossRef]

29. McLean, M.R.; Addis, M.A. Wellbore stability analysis: A review of current methods of analysis and their field application. In Proceedings of the SPE/IADC Drilling Conference, Houston, TX, USA, 27 February-2 March 1990; Society of Petroleum Engineers: Richardson, TX, USA, 1990.

30. Weijermars, R. Mapping stress trajectories and width of the stress-perturbation zone near a cylindrical wellbore. Int. J. Rock Mech. Min. Sci. 2013, 64, 148-159. [CrossRef] 
31. Pašić, B.; Gaurina-Međimurec, N.; Matanović, D. Wellbore instability: Causes and consequences. Rud. Geološko Naft. Zb. 2007, 19, 87-98.

32. Bowes, C.; Procter, R. Drillers Stuck Pipe Handbook; Schlumberger: Ballater, UK, 1997.

33. Weijermars, R. Stress cages and fracture cages in stress trajectory models of wellbores: Implications for pressure management during drilling and hydraulic fracturing. J. Nat. Gas Sci. Eng. 2016, 36, 986-1003. [CrossRef]

34. Wang, H.; Soliman, M.Y.; Towler, B.F. Investigation of Factors for Strengthening a Wellbore by Propping Fractures. In Proceedings of the IADC/SPE Drilling Conference, Orlando, FL, USA, 4-6 March 2008; Society of Petroleum Engineers: Richardson, TX, USA, 2008; p. 15.

35. Tovar, J.; Bhat, S. Characterization of Stress Caging Effect for Resolving Wellbore Integrity Problems in Fractured Formations-Experimental Results. VII INGEPET 2011 (EXPL-2-JT-02). 2011. Available online: https://www.researchgate.net/publication/281902738_CHARACTERIZATION_OF_THE_STRESS_ CAGING_EFFECT_FOR_RESOLVING_WELLBORE_INTEGRITY_PROBLEMS_IN_FRACTURED_ FORMATIONS_-_EXPERIMENTAL_RESULTS (accessed on 30 June 2019).

36. Zhang, X.; Jeffrey, R.G.; Bunger, A.P. Hydraulic Fracture Growth From a Non-Circular Wellbore. In Proceedings of the 45th U.S. Rock Mechanics/Geomechanics Symposium, San Francisco, CA, USA, 26-29 June 2011; American Rock Mechanics Association: Alexandria, VA, USA, 2011; p. 9.

37. Li, Y.; Weijermars, R. Wellbore stability analysis in transverse isotropic shales with anisotropic failure criteria. J. Pet. Sci. Eng. 2019, 176, 982-993. [CrossRef]

38. Weijermars, R.; Wang, J.; Nelson, R. Elastic anisotropy in shale formations and its effect on near-borehole stress fields and failure modes. Earth-Sci. Rev. 2019, in press. [CrossRef]

39. Wang, J.; Weijermars, R. Expansion of Horizontal Wellbore Stability Model for Elastically Anisotropic Shale Formations With Anisotropic Failure Criteria: Permian Basin Case Study. In Proceedings of the 53rd U.S. Rock Mechanics/Geomechanics Symposium, New York, NY, USA, 23-26 June 2019; American Rock Mechanics Association: Alexandria, VA, USA, 2019.

40. Klee, G.; Rummel, F.; Williams, A. Hydraulic fracturing stress measurements in Hong Kong. Int. J. Rock Mech. Min. Sci. 1999, 36, 731-741. [CrossRef]

41. Kirsch, G. Die theorie der elastizität und die bedürfnisse der festigkeitslehre. Z. Ver. Dtsch. Ing. 1898, 42, 797-807.

42. Zoback, M.D.; Barton, C.A.; Brudy, M.; Castillo, D.A.; Finkbeiner, T.; Grollimund, B.R.; Moos, D.B.; Peska, P.; Ward, C.D.; Wiprut, D.J. Determination of stress orientation and magnitude in deep wells. Int. J. Rock Mech. Min. Sci. 2003, 40, 1049-1076. [CrossRef] 